OPEN ACCESS

Edited by:

Panagiotis Papanagiotou, Bremen-Mitte Clinic, Germany

Reviewed by:

loannis loannidis,

Hygeia Hospital, Greece

Alberto Maud

Texas Tech University Health Sciences

Center El Paso, United States

${ }^{*}$ Correspondence:

Jinlu Yu

jlyu@jlu.edu.cn

orcid.org/0000-0003-2329-7946

Specialty section:

This article was submitted to

Endovascular and Interventional

Neurology,

a section of the journal

Frontiers in Neurology

Received: 19 August 2021

Accepted: 22 September 2021

Published: 26 October 2021

Citation:

Zhang K, Li C, Hou K and Yu J (2021)

Role of the Cervical Anterior Spinal Artery in the Endovascular Treatment of Vascular Diseases: Bystander,

Accomplice, Victim, or Friend?

Front. Neurol. 12:761006

doi: 10.3389/fneur.2021.761006

\section{Role of the Cervical Anterior Spinal Artery in the Endovascular Treatment of Vascular Diseases: Bystander, Accomplice, Victim, or Friend?}

\author{
Kun Zhang ${ }^{1}$, Chao $\mathrm{Li}^{2}$, Kun $\mathrm{Hou}^{3}$ and Jinlu Yu ${ }^{3 *}$ \\ ${ }^{1}$ Department of Cerebrovascular Disease, Henan Provincial People's Hospital, Zhengzhou University, Zhengzhou, China, \\ ${ }^{2}$ Department of Neurology, First Hospital of Jilin University, Changchun, China, ${ }^{3}$ Department of Neurosurgery, First Hospital \\ of Jilin University, Changchun, China
}

The cervical anterior spinal artery (ASA) is a very important artery arising from the intracranial vertebral artery (VA). It can play different roles in endovascular treatment (EVT) of spinal vascular diseases. The current understanding of these roles is incomplete; therefore, we performed this review. We found that cervical ASA can be involved in many spinal vascular diseases, such as arteriovenous fistula (AVF), arteriovenous malformation (AVM), and aneurysm, and can serve as a collateral channel in proximal VA occlusion. In AVF and AVM, when the cervical ASA is involved, it often plays the role of an accomplice or victim because it acts as the feeder or as a bystander that does not provide blood flow to the AVF and AVM. In cervical ASA aneurysm, the ASA is a victim. During EVT of $V A$ aneurysms or stenoses, the cervical ASA ostia can be covered or occluded, resulting in ASA ischemia. In this situation, the ASA is a victim. In VA occlusion or the subclavian steal phenomenon, the cervical ASA can serve as a collateral channel to provide blood flow to the posterior circulation. In this case, the ASA plays the role of a friend. According to the role of the cervical ASA in spinal vascular diseases, EVT should be determined "case by case." Most importantly, when EVT is performed to treat these diseases, the cervical ASA axis must be preserved. Therefore, understanding the role of the cervical ASA in spinal vascular diseases is crucial.

Keywords: cervical anterior spinal artery, vascular disease, endovascular treatment, arteriovenous malformation, arteriovenous fistula

\section{INTRODUCTION}

The cervical anterior spinal artery (ASA) arises from the intracranial vertebral artery (VA) and provides blood to the anterior two-thirds of the spinal cord (1). It may be involved in many cervical spinal vascular diseases, such as arteriovenous fistula (AVF), arteriovenous malformation (AVM), and aneurysm (2-4). In addition, in VA occlusion or the subclavian steal phenomenon, the cervical ASA can serve as a collateral channel (5).

Currently, endovascular treatment (EVT) has become an effective method for cervical spinal vascular diseases (6). However, the EVT can damage the cervical ASA. For instance, during flow diversion (FD) deployment, VA stent angioplasty, or balloon angioplasty, the cervical ASA ostia can be covered or occluded (7). Therefore, the role of the cervical ASA is very complex. It can be an accomplice, victim, bystander, or friend. 
According to the role of the cervical ASA in spinal vascular diseases, EVT should be determined "case by case." It is of most importance that the cervical ASA axis be preserved (8). The current understanding of the role of the cervical ASA in EVT of spinal vascular diseases is insufficient. Therefore, we performed this important review.

\section{CERVICAL ASA ANATOMY}

The typical ASA originates as a common trunk from paired VAs, and its origin is $5-17 \mathrm{~mm}$ proximal to the vertebrobasilar junction, angiographically presenting with a characteristic midline hairpin $(5,9,10)$. High anatomical variability of the ASA origin exists, and it often has either a predominance of one ramus over the other or a sole unilateral ramus of origin $(11,12)$. The Santos-Franco et al. study reported a less typical bilateral origin of the ASA (13).

The ASA is not a single artery but a series of anastomotic vascular loops. In the cervical region, the ASA is continuous, unlike that in the thoracic region $(12,14,15)$. The cervical ASA requires segmental radiculomedullary arteries from the VA (C1C6), the ascending cervical artery (C3-C4), and the deep cervical artery $(\mathrm{C} 3-\mathrm{C} 7)(10,16,17)$. In the craniocervical junction, the ascending pharyngeal artery $(\mathrm{C} 2-\mathrm{C} 4)$ and the occipital artery $(\mathrm{C} 1-\mathrm{C} 2)$ can be involved in the blood supply to the ASA $(18,19)$. In addition, the supreme intercostal artery can be involved as a feeder to the ASA in the cervical region (C7) (20).

In the cervical region, the radiculomedullary artery from $\mathrm{C} 4-$ C7 is usually the most predominant and is called the artery of cervical enlargement $(16,21)$. In addition to the VA, the artery of cervical enlargement can arise as a segmental branch of the ascending or deep cervical arteries (22-24). The angiographic anatomy of the cervical ASA is shown in Figure 1.

\section{CERVICAL SPINAL AVFS}

Cervical spinal AVFs vary and can be divided into dural AVFs (DAVFs), radicular AVFs, epidural AVFs, and perimedullary AVFs (PAVFs); they are located on the inner or outer surface of the dura, on the spinal nerves, or on the spinal cord $(6,25-28)$. In cervical AVFs, the ASA can be an active accomplice. In the Hiramatsu et al., study, half of high cervical AVFs were fed by the ASA (6).

\section{Cervical DAVFs}

Spinal DAVFs are located near or within the dura of the nerve sleeve, connecting radiculomeningeal arteries with the radicular vein that drains into the perimedullary vein (29). Cervical DAVFs occur in $<6 \%$ of spinal DAVFs (30-33). In most cervical DAVFs, the ASA acts as a bystander (34-36). Rarely, the ASA can be an accomplice. In the report of Adrianto et al., 2.4\% of cervical DAVFs had a concomitant origin of the ASA with the feeder (37).

Currently, EVT is feasible $(31,32)$. However, when cervical DAVFs originate from the radicular branch that supplies both the fistula and ASA, the EVT must be chosen carefully (31). During EVT, liquid embolic materials can be chosen, and they should penetrate the vein beyond the fistula without disturbing the ASA. Therefore, the microcatheter should be in a wedged position to ensure no contrast reflux into the ASA (36). In EVTs for other AVFs and AVMs, the microcatheter should be in the wedged position.

For cervical DAVFs, the liquid material N-butyl-2cyanoacrylate (NBCA) and Onyx (Medtronic, Irvine, California, USA) can be used, and NBCA with a lipiodol mixture at a $20-30 \%$ concentration is preferred (31). Onyx is limited by the difficulty in achieving venous penetration; at this time, using a balloon-occlusion catheter to assist Onyx casting is helpful, which can promote Onyx penetration (38).

\section{Radicular AVFs}

Radicular AVFs are located on the intradural nerve root and are fed by radicular and/or radiculomeningeal arteries that drain into the radicular vein $(39,40)$. Cervical radicular AVFs have an angioarchitecture similar to that of spinal DAVFs. However, they are different. First, the radicular AVF site is on the nerve root, and the $\mathrm{C} 1$ or $\mathrm{C} 2$ level is the preferred location $(39,40)$. Second, in radicular AVFs, the ASA often joins the same radicular artery $(6,40)$. Third, in radicular AVFs, a long-distance perimedullary draining vein is uncommon $(6,39,40)$. Because radicular AVFs often have an ASA blood supply, EVT has a higher risk.

\section{Cervical Epidural AVFs}

Spinal epidural AVFs feature a dilated epidural venous pouch that is supplied by paraspinal or paravertebral arteries and drains into epidural plexuses (41-43). Cervical epidural AVFs are not uncommon (Figure 2). In the report of Asai et al., 30.8\% of epidural AVFs were located in the cervical region and often in the lateral spinal canal, even with bone involvement (44-46). They are divided into types A and B: type A has a small venous pouch with intradural venous drainage, often with congestive myelopathy, and type B has a large venous lake without intradural drainage, often with compressive myelopathy (47-50).

In cervical epidural AVFs, especially in high locations, spinal pial arteries often have a common origin with the feeder; therefore, the ASA can be involved as an accomplice (50,51). In the Hiramatsu et al., study, 57\% of high cervical epidural AVFs were fed by the ASA (6).

EVT is appropriate for cervical epidural AVFs. Transarterial EVT is mostly applied, and liquid embolic material must be avoided in the ASA $(48,52,53)$. Sometimes, transarterial EVT of high/middle cervical epidural AVFs is difficult, as these AVFs are usually fed by small and short VA branches $(48,54)$. If there is a fistulous connection, transvenous EVT is a good choice, and the use of a proximal balloon to control high blood flow followed by coiling or liquid embolic material embolization is helpful $(51,55)$.

\section{Cervical PAVFs}

PAVFs result from direct communication between feeding arteries and enlarged draining veins without the intervening nidus; they are intradural but extramedullary, and in the cervical region, they are usually located on the anterior or lateral surface of the spinal cord (56). The shunting points can be single or multiple (57). Cervical PAVFs are not uncommon; in the Mizutani et al., study, PAVFs in the cervical region accounted for 


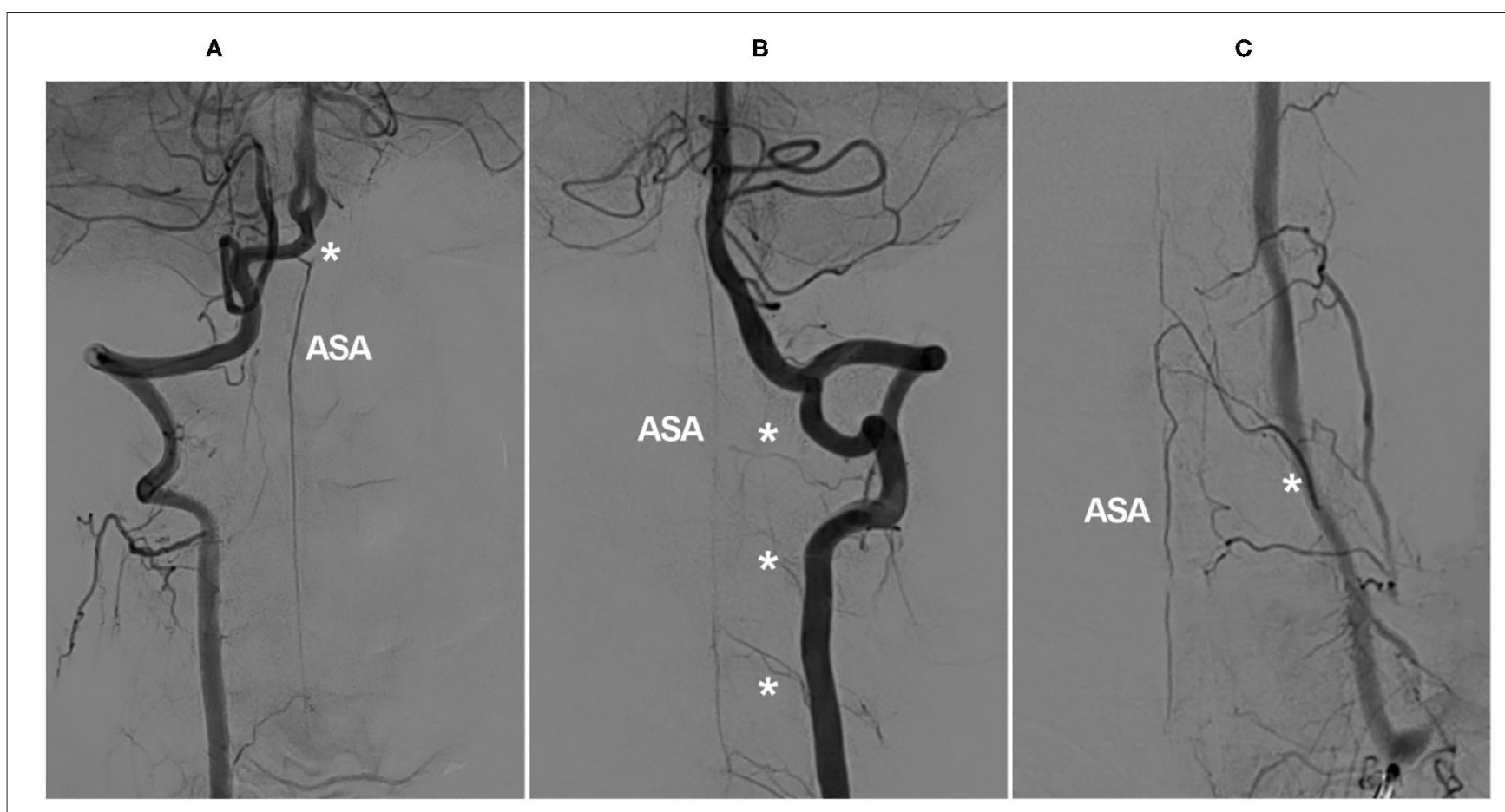

FIGURE 1 | Angiographic cervical ASA anatomy. (A) VA angiogram showing a long-distance ASA arising from intracranial VA termination (asterisk). (B) VA angiogram showing that the ASA is relayed by the continuous segmental radiculomedullary arteries (asterisks). (C) VA angiogram showing the artery of cervical enlargement (asterisk). ASA, anterior spinal artery; VA, vertebral artery.

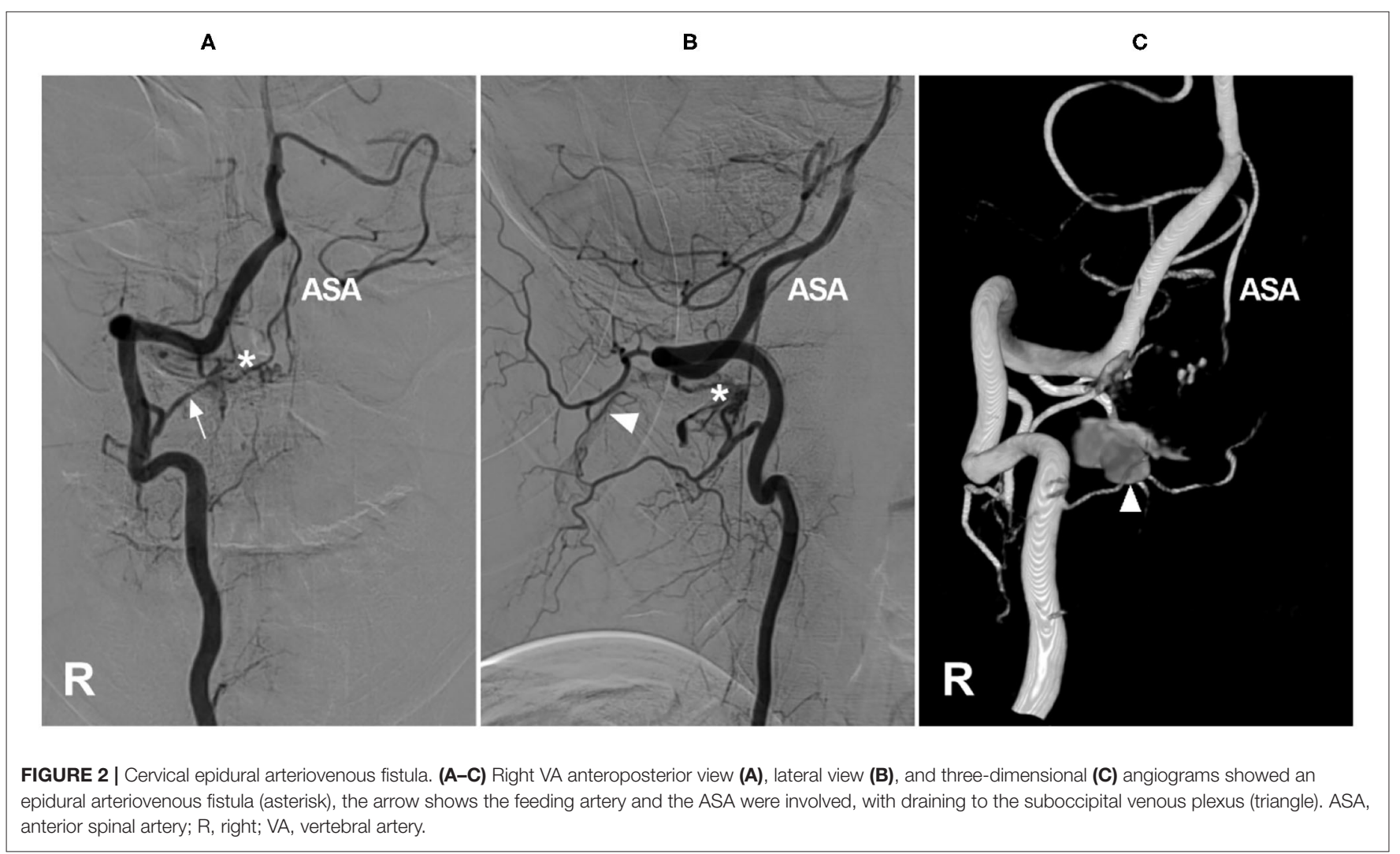


A

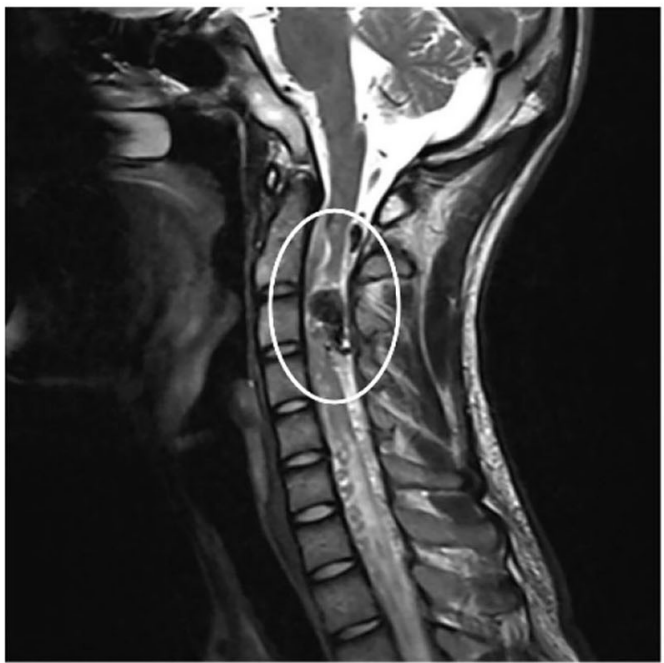

C

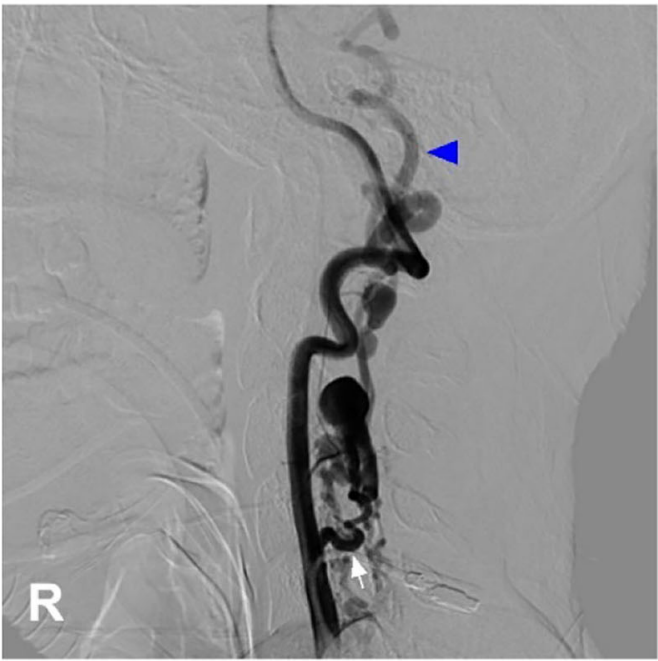

E

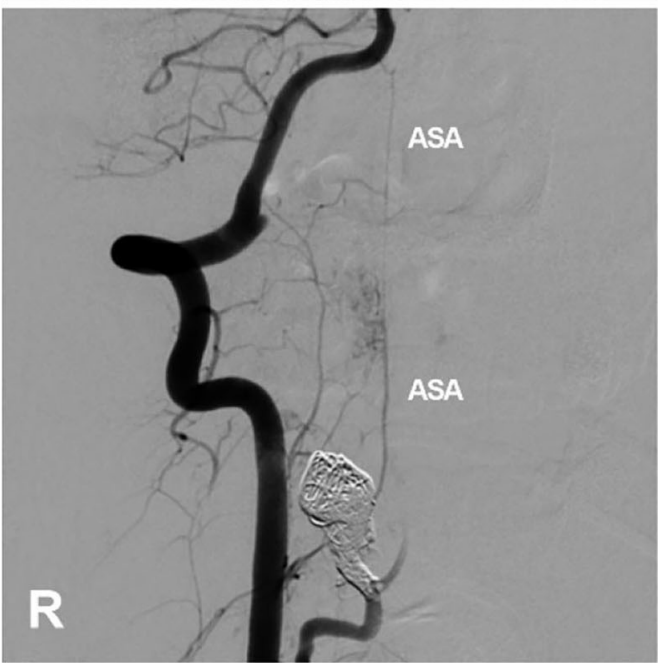

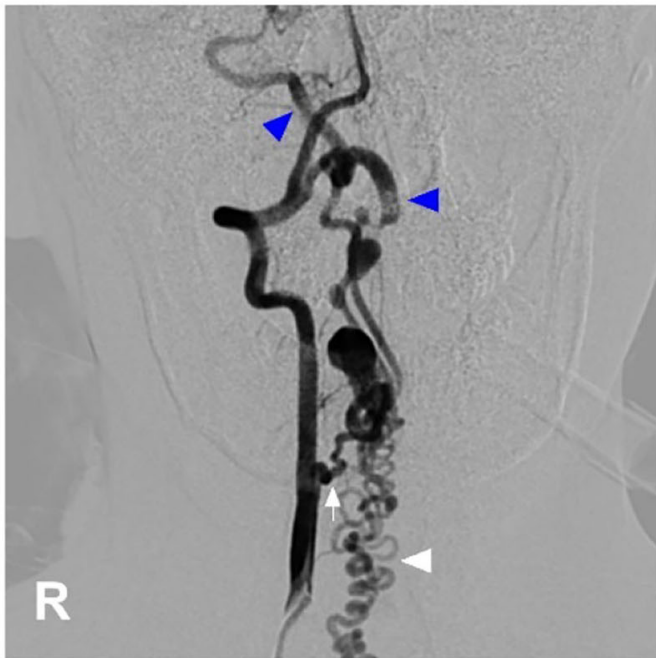

B

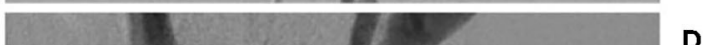

D
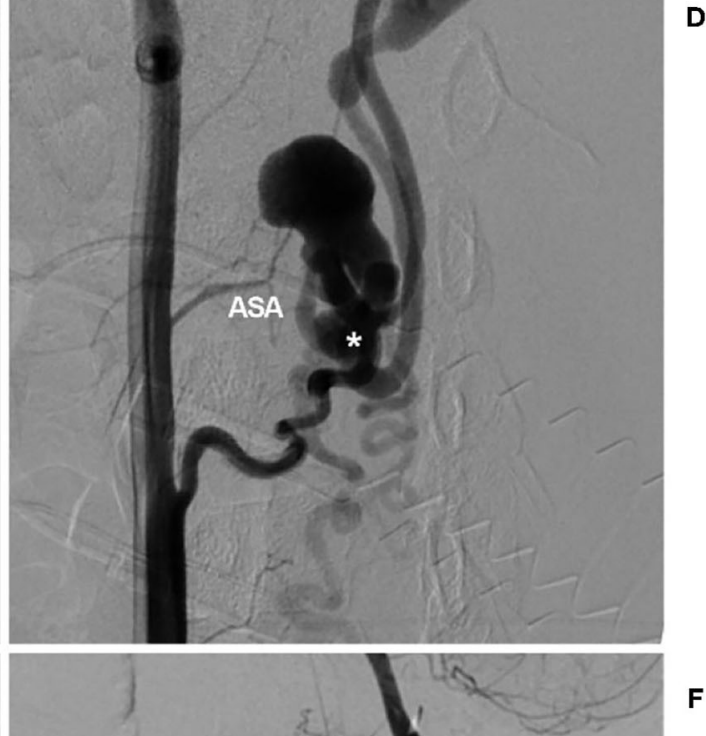

$\mathbf{R}$

FIGURE 3 | EVT of a cervical perimedullary arteriovenous fistula. (A) MRI showed a PAVF near the C3 level (circle). (B,C) Right VA anteroposterior view (B) and lateral view (C) angiograms showed that the PAVF was mainly supplied by a dilated radiculomeningeal artery (arrow), with draining to the cranium (blue triangles) and lower neck (white triangle), and that the draining veins were dilated. (D) An angiogram showed the shunt point of the PAVF (asterisk). The ASA could be seen as a bystander. (E,F) Right VA anteroposterior view (E) and lateral view (F) postoperative angiograms showed that the PAVF was embolized by coiling. The ASA remained intact as a bystander. ASA, anterior spinal artery; EVT, endovascular treatment; MRI, magnetic resonance imaging; PAVF, perimedullary arteriovenous fistula; R, right; VA, vertebral artery. 
A

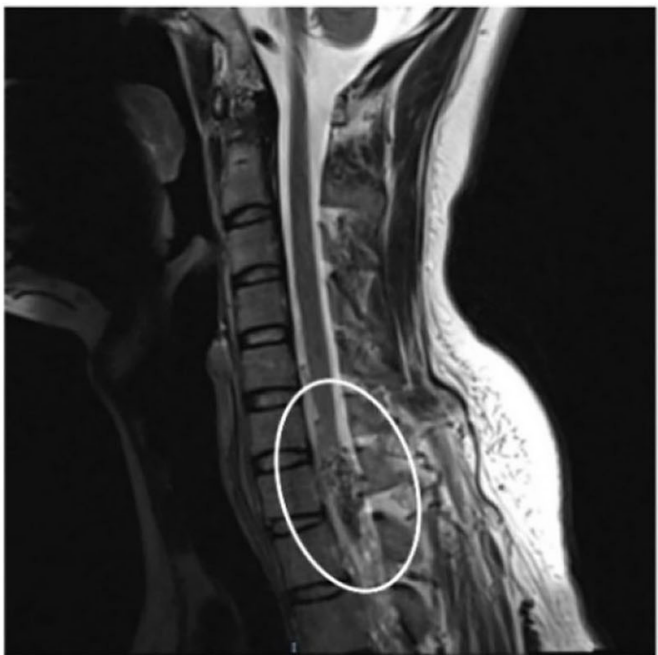

C

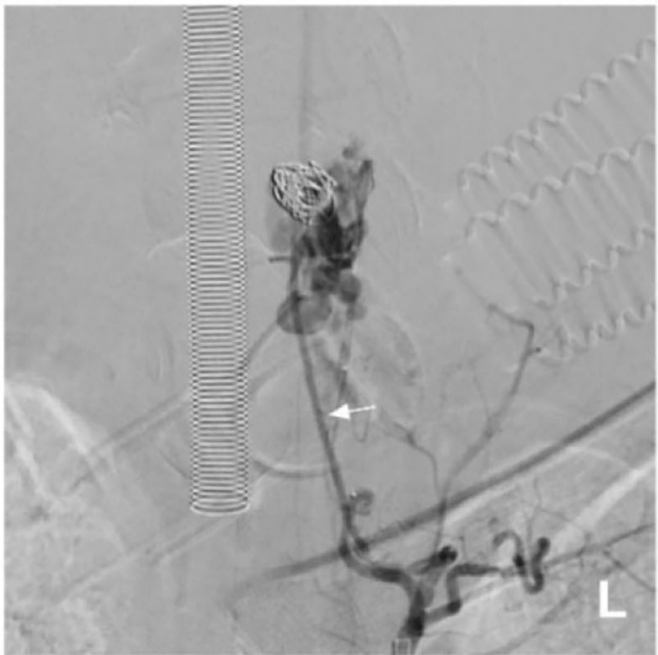

E

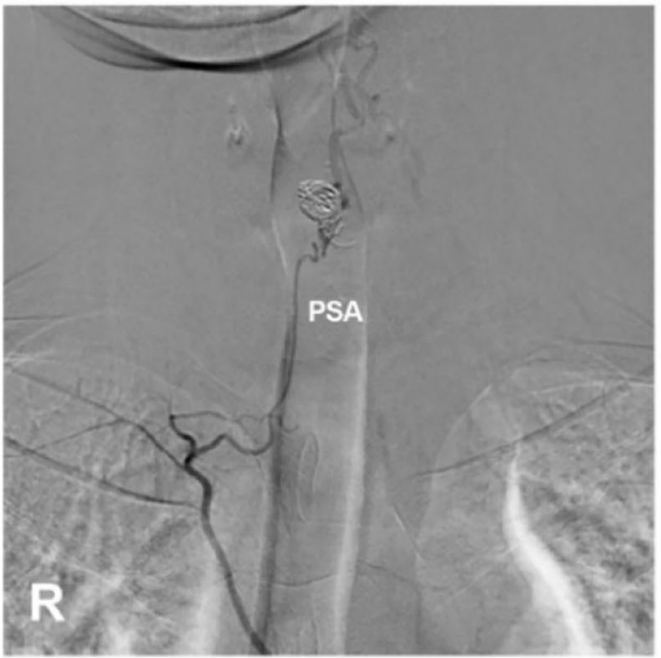

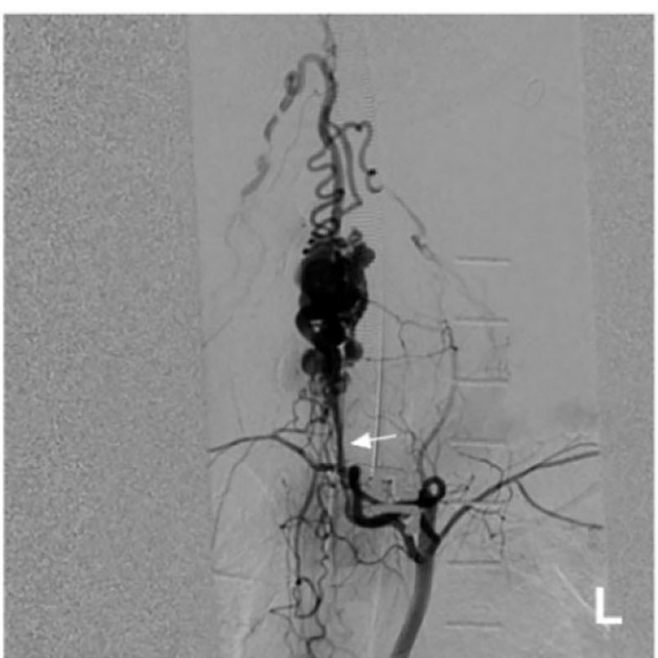

B
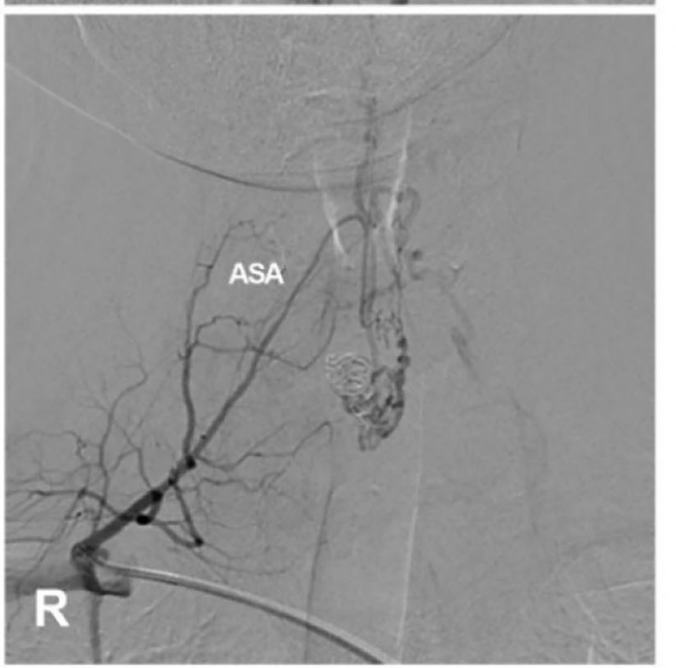

D

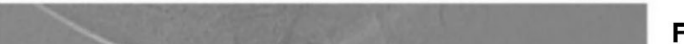

$\mathbf{F}$

FIGURE 4 | EVT of a cervical intramedullary glomus arteriovenous malformation. (A) MRI showed an intramedullary glomus AVM near the C7 level (circle). (B) Left angiogram of the supreme intercostal artery showed that the AVM was mainly supplied by the dilated radiculomeningeal artery (arrow). (C) The aneurysm in the AVM was coiled first via the radiculomeningeal artery (arrow), and then the NBCA was cast. (D-F) Six-month follow-up angiograms showed that the AVM had decreased. Radiotherapy was recommended. (D) shows an angiogram via the right costocervical trunk revealing that the ASA was involved as the feeder. (E,F) show angiograms via the left and right supreme intercostal arteries, revealing that the PSA was the feeder. AVM, arteriovenous malformation; ASA, anterior spinal artery; EVT, endovascular treatment; L, left; MRI, magnetic resonance imaging; NBCA, N-butyl cyanoacrylate; PSA, posterior spinal artery; R, right. 
$22.4 \%$ of all PAVFs (2). In the study of Mizutani et al., of pediatric cases, the rate was $11.8 \%$ (2).

The ASA is an active accomplice in cervical PAVFs. In the Endo et al. study of 22 cervical PAVFs, the ASA contributed to shunts in $72.7 \%$ of patients (58). Cervical PAVFs can be divided into three types. Type A PAVFs are small, single-vessel fistulas supplied by a single ASA that mostly occur in adult patients. Types B and C PAVFs are giant, multiple-vessel fistulas supplied by the ASA and posterolateral spinal arteries, with high-flow, enlarged, and tortuous draining veins that occur more often in children $(59,60)$.

Cervical PAVFs can be managed with EVT, and the key aim is ASA preservation as long as possible during fistula obliteration (58, 61, 62). Not all PAVFs are appropriate for EVT. For Type A PAVFs, EVT is difficult because ASA catheterization is problematic; for Types $\mathrm{B}$ and $\mathrm{C}$ PAVFs, transarterial EVT via the ASA may be a safe and effective choice $(57,63)$. Certainly, if the ASA is a bystander in PAVFs, EVT is easy (Figure 3). In addition, the transvenous path can be used (58). Coils and NBCA are preferred for cervical PAVFs because of the short course of the ASA extending from the VA $(64,65)$.

\section{CERVICAL INTRAMEDULLARY GLOMUS AVM}

Spinal glomus AVM is an intramedullary arteriovenous shunt with an intervening nidus $(60,66)$. A cervical location accounts for $\sim 30 \%$ of intramedullary glomus AVMs with multiple feeding vessels arising from the ASA and posterolateral spinal arteries (67-69). The vast majority of intramedullary glomus AVMs are diffuse, and they are comparatively smaller than juvenile-type AVMs (68). The ASA is often an active accomplice. In the Mizutani et al., study including 69 glomus intramedullary AVMs, $100 \%$ of the ASAs were involved (2).

Currently, EVT is a good option for cervical glomus AVMs (70). For ideal EVT, only the nidus is eliminated, while the ASA axis is maintained (71). If the ASA is not chosen as the pathway to perform EVT, then EVT is easy (Figure 4). If EVT is performed via the ASA, the embolic agent used is NBCA or Onyx, provided that the microcatheter tip can be placed within the nidus (7274). If the microcatheter tip can be placed close to the nidus but beyond the angiographically visible normal ASA, NBCA is still a good choice (75).

However, the goal of complete EVT is difficult because the main feeding vessel of the cervical glomus AVM, a perforating artery from the ASA, also serves as a feeding vessel to the spinal cord (76). EVT can be accompanied by inadvertent proximal reflux of the embolic material $(72,77)$. Therefore, many glomus AVMs cannot be cured by EVT; more often, EVT is adopted extensively as a palliative treatment (78).

\section{CERVICAL ASA ANEURYSM}

ASA aneurysms are rare and are mainly located in the upper cervical segment $(4,79-82)$. They are typically dissections and can be divided into isolated and flow-related types $(83,84)$. The

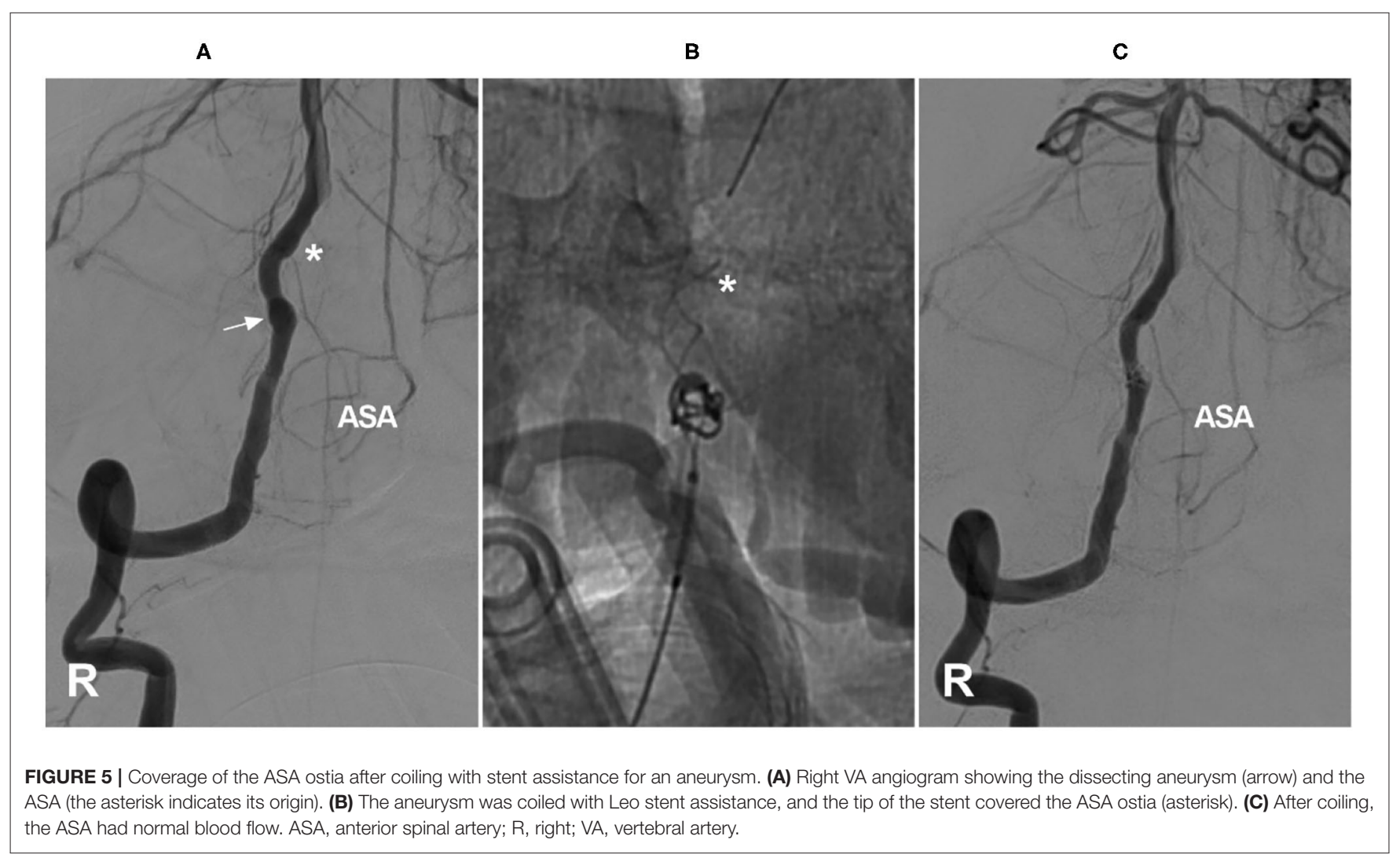


flow-related type is common. In the Madhugiri et al., study, $20.8 \%$ of spinal aneurysms were associated with AVM, and $7.8 \%$ of aneurysms were isolated (80). Flow-related aneurysms are found in $29 \%$ of glomus AVMs and $10 \%$ of spinal PAVFs $(85,86)$. Even cervical epidural AVFs can be associated with ASA aneurysms (50).

EVT for isolated ASA aneurysms remains difficult because the catheter system must be constructed via the small-caliber ASA (3). For flow-related aneurysms of the ASA, because the ASA is often dilated, EVT may be feasible (87). When the aneurysm is located at the bifurcation between a large artery supplying the AVM and the ASA, the aneurysm may be suited for coiling
(88). If liquid embolic material is used, the ASA axis needs to be preserved, and only superselective embolization of the branches harboring the aneurysm can be allowed $(87,89)$.

In addition, conservative management is a reasonable option for ASA aneurysms $(90,91)$. Even flow-related ASA aneurysms can be managed conservatively. In an Ichiro et al. report, a ruptured aneurysm of the ASA regressed after feeding to an AVF after EVT eliminated the AVF and reduced the hemodynamic stress on the aneurysm (50). The reduction of hemodynamic stress is effective, and even ruptured ASA aneurysms can be cured by hemodynamic remodeling with FD placed in the ipsilateral VA (92).

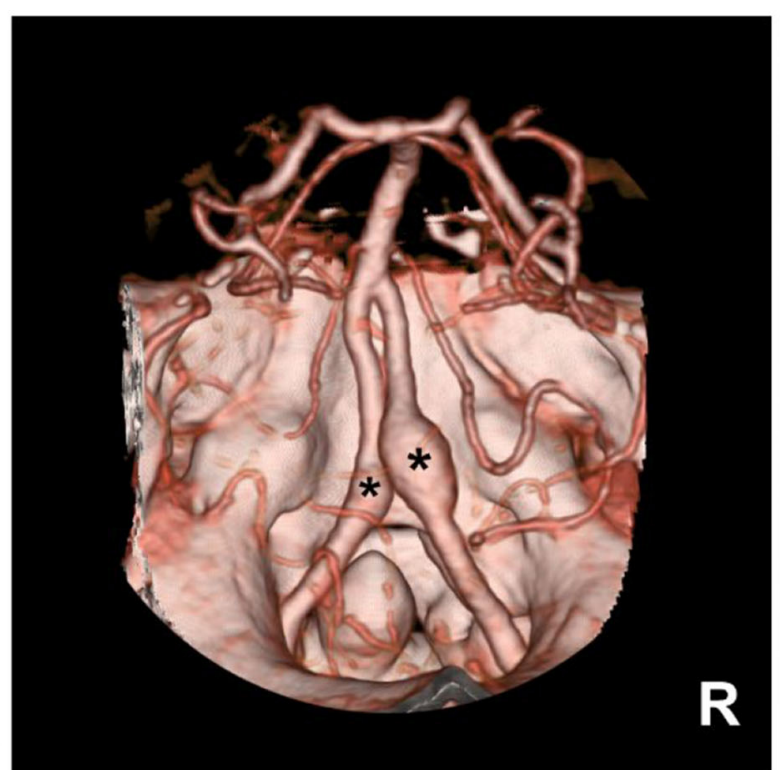

c

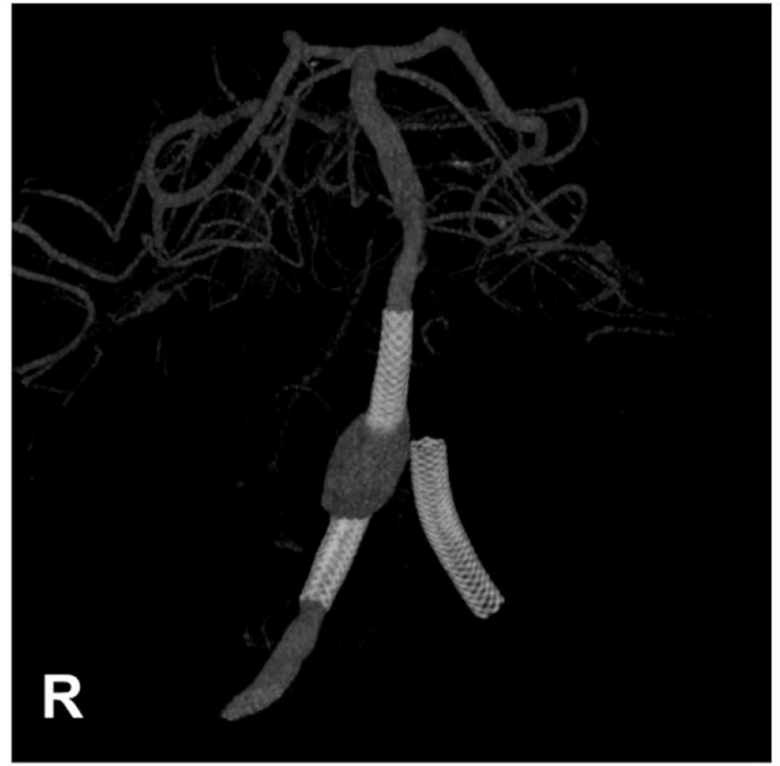

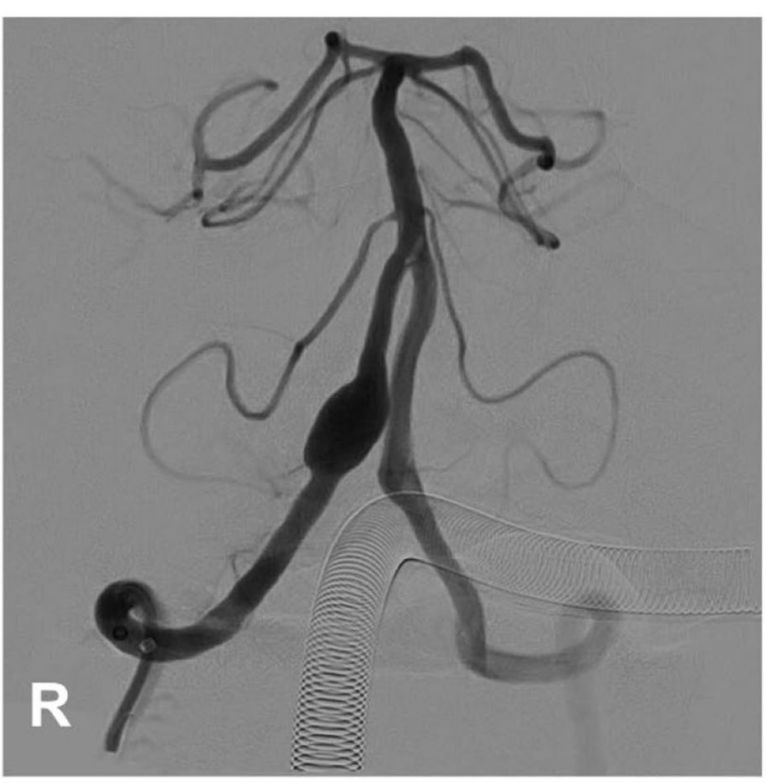

B

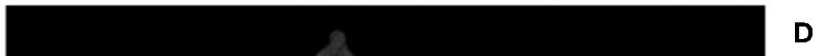

FIGURE 6 | Flow diversion deployment to treat bilateral VA aneurysms. (A,B) CTA (A) and VA angiogram (B) showing bilateral VA dissecting aneurysms (asterisks in (A)); in (B), the ASA was not observed. (C,D) Angiogram of the bilateral VA showing the flow diversions deployed to treat the aneurysms. ASA, anterior spinal artery; CTA, computed tomography angiography; L, left; R, right; VA, vertebral artery. 


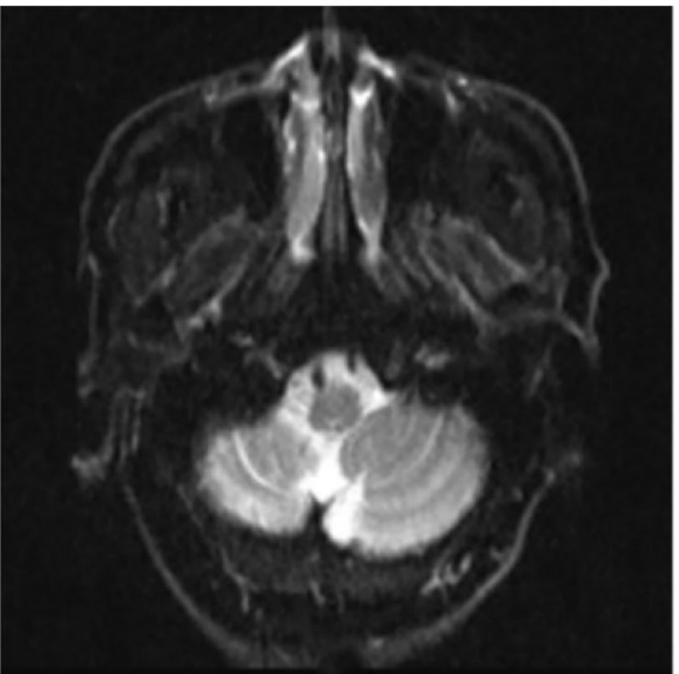

C

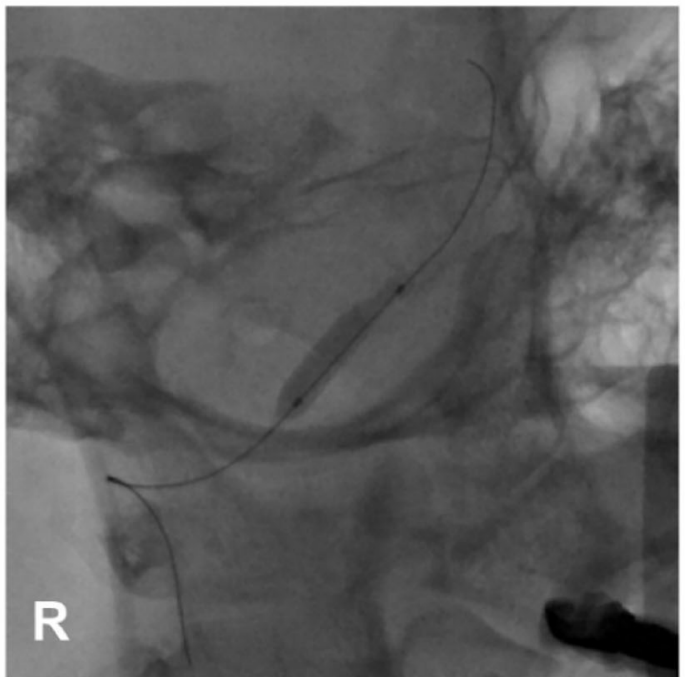

E

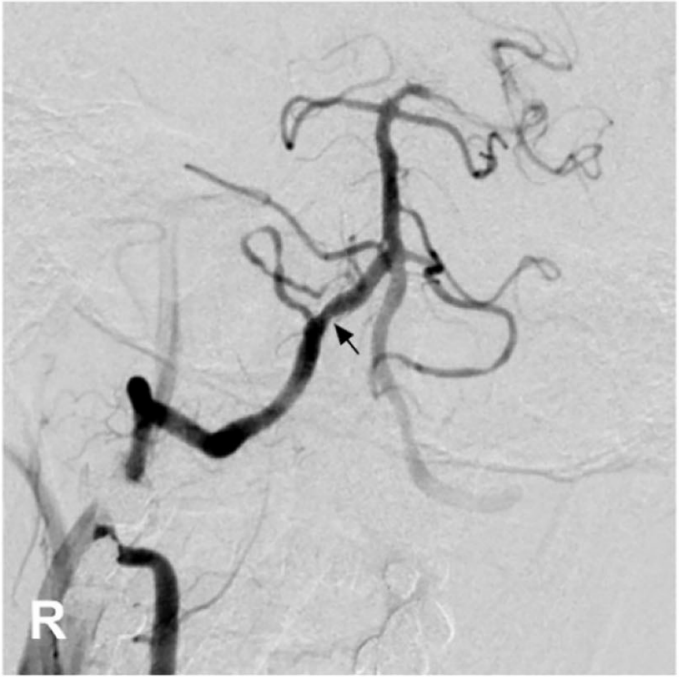

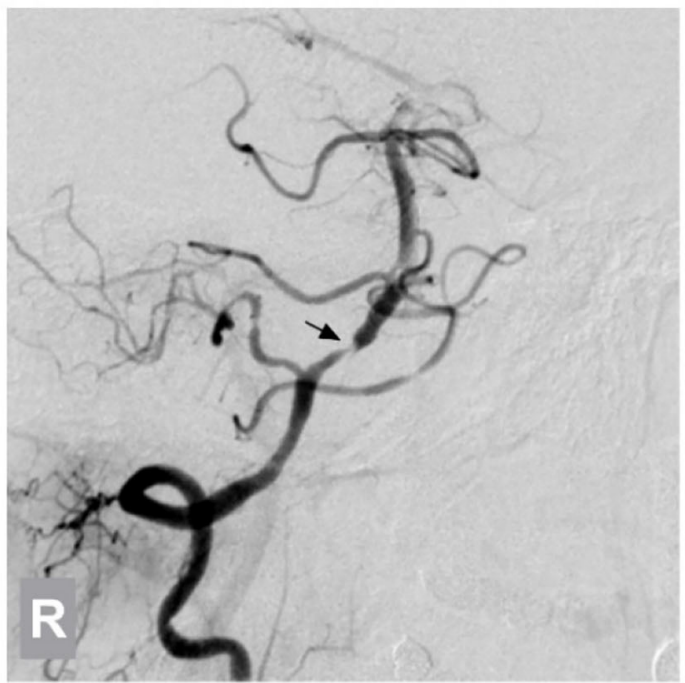

B

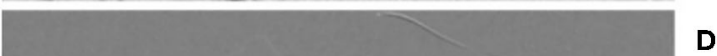

D
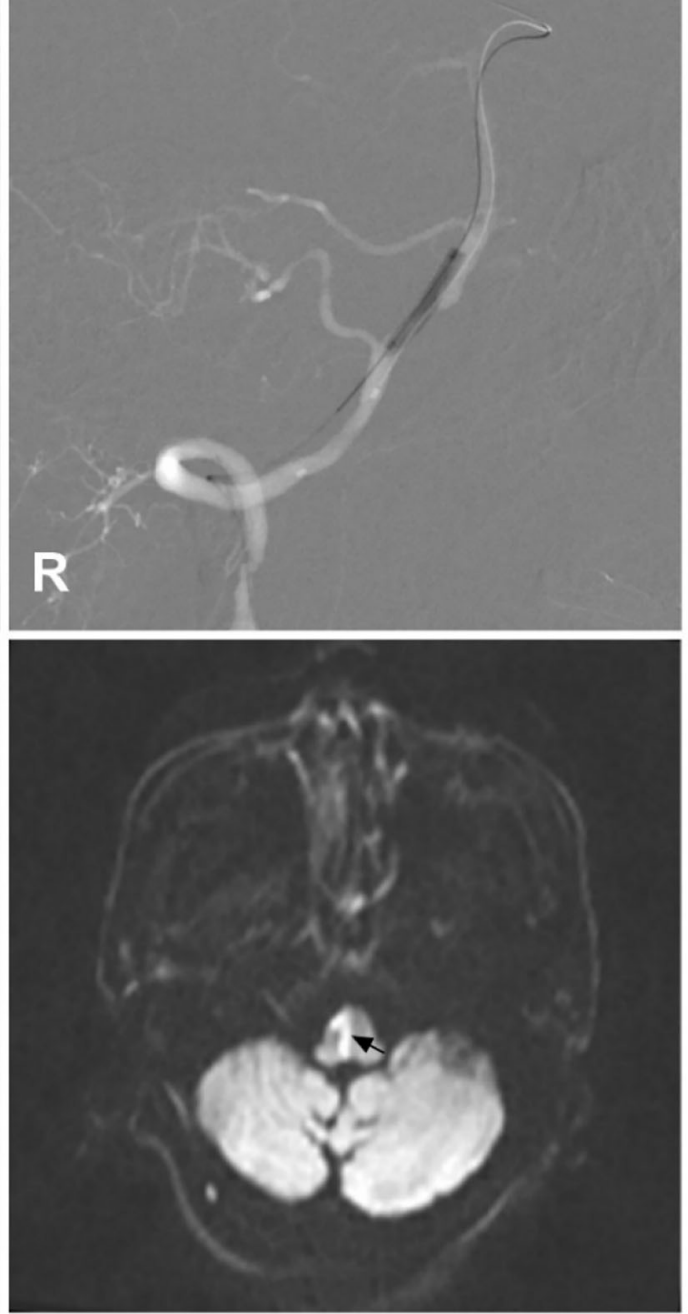

FIGURE 7 | Medulla oblongata infarction from ASA ischemia after stent angioplasty. (A) MRI showed a normal medulla oblongata. (B) A right VA angiogram showed stenosis (arrow) of the VA beyond the posterior inferior cerebellar artery. (C) Balloon angioplasty was performed. (D) A balloon-expandable stent was deployed. (E) After stent angioplasty, the stenosis was relieved (arrow). (F) Postoperative MRI showed acute medulla oblongata infarction (arrow), indicating ASA ischemia and resulting in locked-in syndrome. ASA, anterior spinal artery; MRI, magnetic resonance imaging; R, right; VA, vertebral artery. 

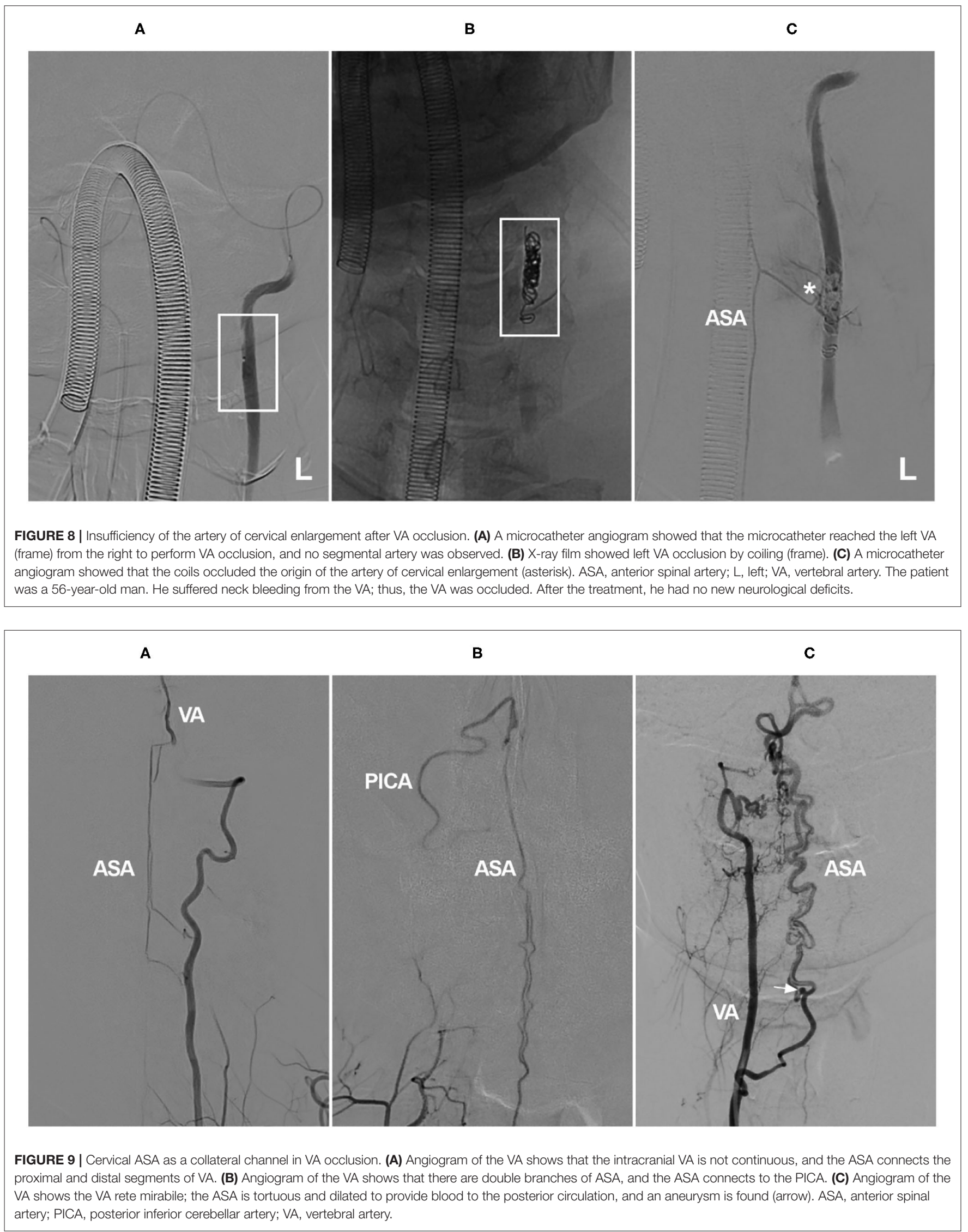


\section{CERVICAL ASA ISCHEMIA FROM ASA OCCLUSION OR COVERAGE BY EVT}

During EVT, the ASA ostia can be occluded or covered, resulting in medullary ischemia. The procedures include conventional stent-assisted coiling, VA trapping, FD deployment, VA stent angioplasty, etc. In such cases, the ASA is a victim.

\section{Stent-Assisted Embolization of VA Aneurysms and VA Trapping}

According to Wang et al., VA aneurysms can be classified into three types: type I aneurysms, located distal to the posterior inferior cerebellar artery (PICA); type II aneurysms, located at the PICA origin; and type III aneurysms, located proximal to the PICA (93). In theory, EVT for type III aneurysms can result in occlusion of the ASA ostia. However, multiple segmental arterial supplies of the cervical spinal cord make the ASA relatively resistant to ischemia (94-96).

The metal coverage of conventional intracranial stents is low; with their assistance, coiling for VA aneurysms is safe for the
ASA (Figure 5) (97). However, when the ASA originates from the aneurysm, coiling with sacrifice of the ASA should be conducted with caution (11). If the collateral circulation is insufficient, occlusion of an unpaired ASA can result in bilateral medial medullary syndrome $(11,98,99)$.

Is VA trapping safe? In an Aihara et al., study on the predictive factors of medullary infarction after VA trapping for aneurysms, $30 \%$ of the patients suffered medullary infarction. The study showed that the risk was not the length but the anatomical location of VA trapping; therefore, preservation of the ASA origin can reduce the risk of medullary infarction (100). In addition, it is worth noting that, sometimes, despite preserved flow of the ASA, spinal cord hemodynamic infarction can occur due to hypoperfusion (11).

\section{FD Deployment}

The VA has fewer critical perforators, and FD deployment in the VA is always considered a safe choice. However, in theory, because the occlusion of an unpaired ASA can result in medial medullary syndrome, FD deployment in the VA still causes

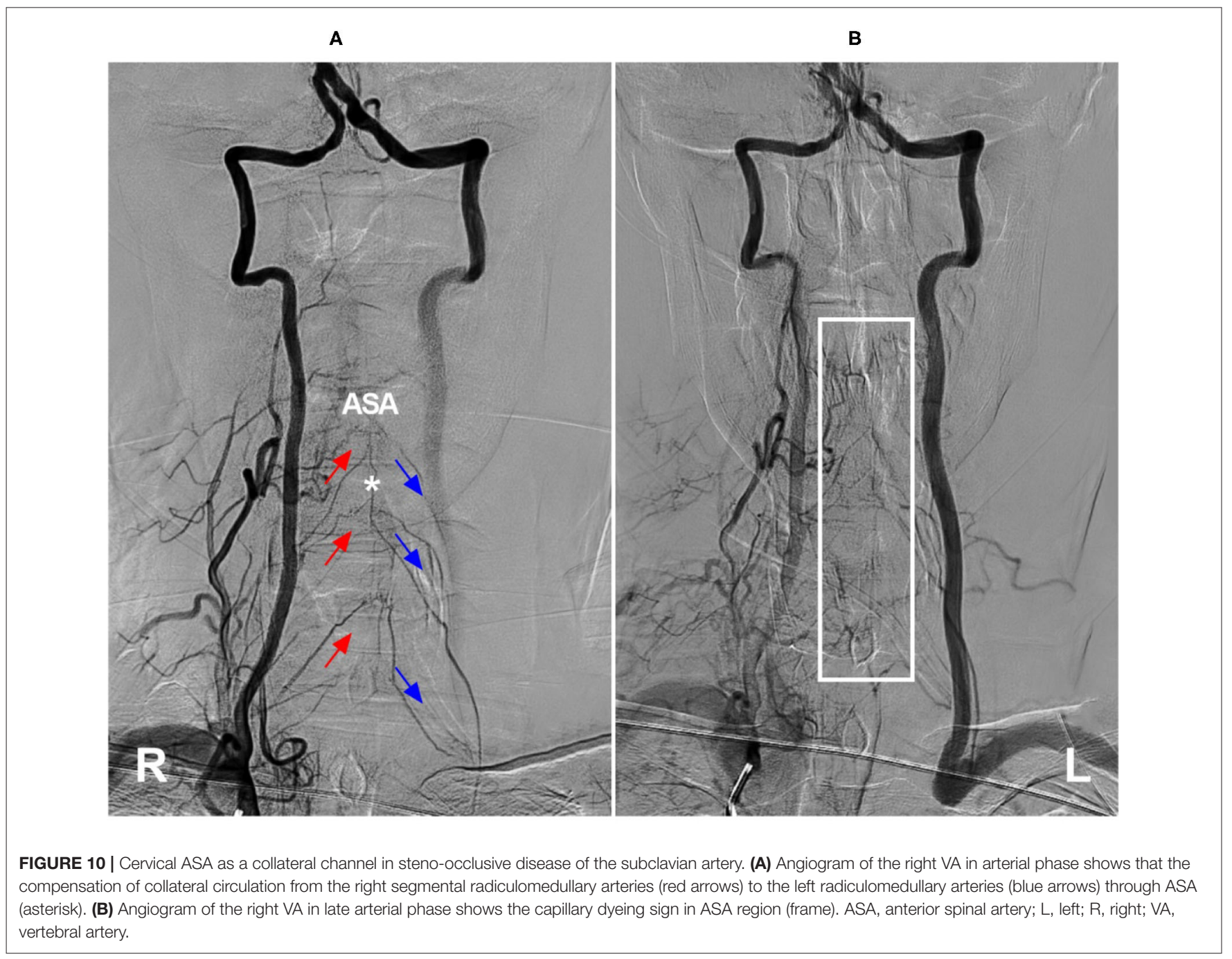


concern regarding medullary ischemia from ASA ostia coverage $(101,102)$.

What is the consequence in the real world? In a recent multicenter study by Adam et al., VA aneurysms were treated by FD, ASAs were identified in $80.9 \%$ of aneurysms, $55.6 \%$ of ASAs were covered by the FD, and patency after FD coverage at the last follow-up was $89.2 \%$ for ASAs. The study showed that FD deployment with coverage of the ASA was not associated with higher rates of occlusion of the ASA or any instances of cord infarction (7).

Considering the potential risk factor, FD deployment should likely be avoided in cases of an unpaired ASA, and FD with coverage of the sole ASA is likely not a favorable treatment option (11). In cases of paired ASAs, FD use could be more liberal; however, FD deployment in bilateral VAs necessitates more caution (Figure 6).

\section{VA Stent Angioplasty and Balloon Angioplasty}

Acute VA dissection can result in occlusion of the ASA $(94,103)$. Therefore, there is a danger that intracranial VA stent angioplasty or balloon angioplasty of the VA may injure the ASA ostia, where the dissection formed. In the study of Wang et al. of 55 cases with intracranial VA stenosis, balloon angioplasty and stent angioplasty resulted in $9.1 \%$ of cases with perforator injuries of the VA, resulting in ischemic complications, most of which resulted from ASA injury (104). Therefore, the ASA should be identified. If the ASA is not seen, dissection of its region of origin should be avoided (Figure 7).

\section{Injury From a Supporting Catheter}

In general, the occlusion of an artery feeding the cervical regions rarely results in an infarction of the spinal cord, as these areas have well-vascularized networks (105). However, similar to occlusion of the artery of Adamkiewicz, which can result in spinal cord infarction, insufficiency of the artery of cervical enlargement is a dangerous situation (Figure 8) $(106,107)$.

During EVT via the VA, a larger-sized guiding catheter is often necessary; it can restrict blood flow and produce catheterinduced vasospasm, which can rarely result in thromboemboli and/or hemodynamic insufficiency of the artery of cervical enlargement, resulting in ASA ischemia (24). Therefore, excise VA angiography is recommended, and the catheter should be placed away from the ostia of the artery of cervical enlargement. The guiding catheter should also be continuously flushed with heparinized saline (108).

\section{CERVICAL ASA AS A COLLATERAL CHANNEL}

Proximal VA occlusion at the neck is usually compensated via the thyrocervical, deep cervical, occipital, and ascending pharyngeal arteries (109). Rarely, retrograde flow through the ASA can serve as a collateral channel, especially in chronic bilateral VA

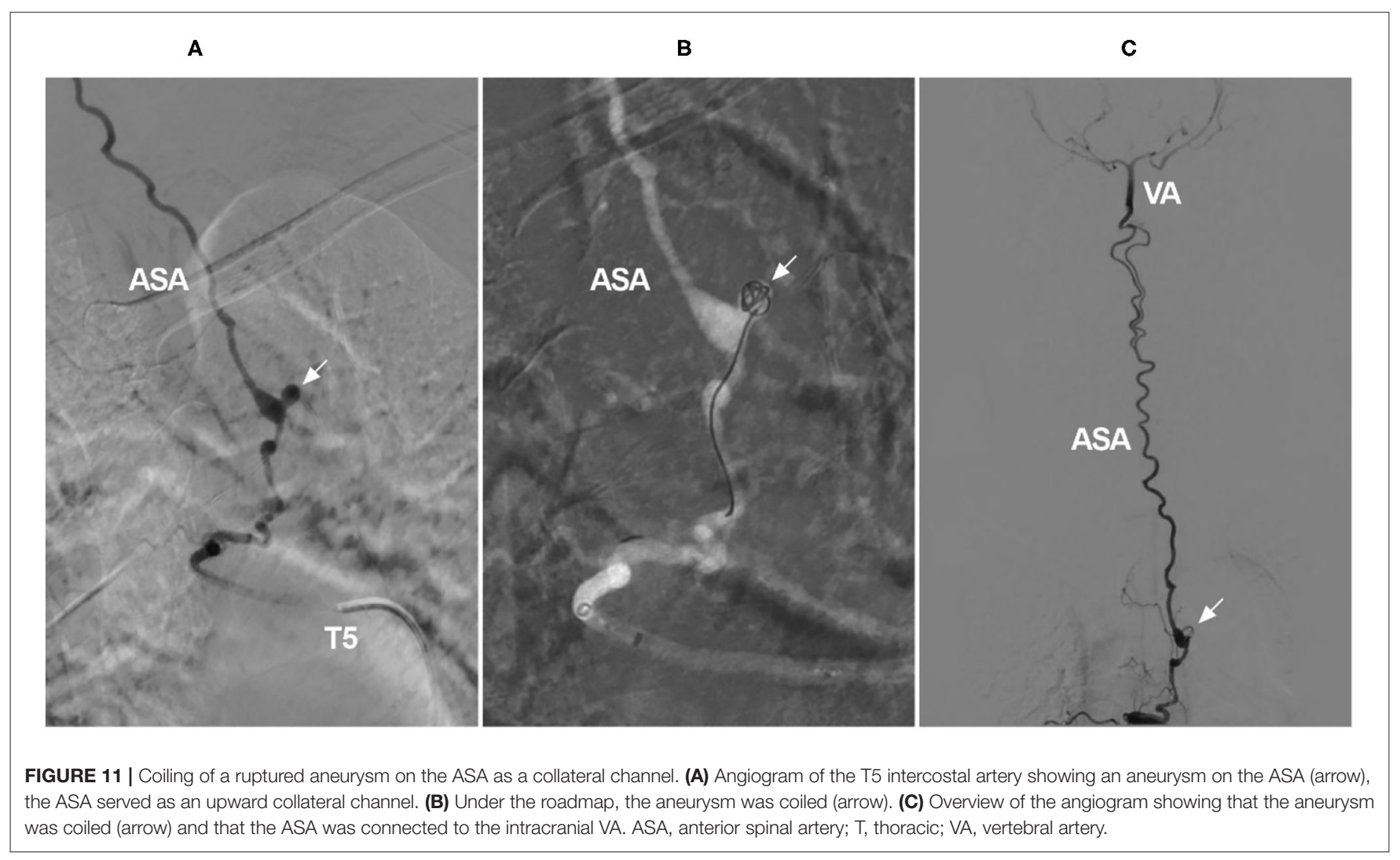


occlusion or a single VA occlusion with other severe stenoses (Figures 9A,B) (5). In addition, in VA rete mirabile, the ASA may also serve as the collateral channel (Figure 9C) (110).

The degree of the ASA collateral channel varies depending on the presence of other collateral routes (109). Due to the small diameter of the ASA, collateral flow through the ASA may be unable to compensate for critical hypoperfusion, resulting in recurrent strokes (111). VA stenting can markedly improve the flow of the posterior circulation; after successful recanalization of the occluded VA, the collateral channel of the ASA may disappear $(5,112)$.

Other than in cases of VA occlusion and rete mirabile, the ASA as a collateral channel can occur in the subclavian steal phenomenon, in which the artery of cervical enlargement may stem from the normal VA to connect to a spinal branch of the contralateral VA or costocervical trunk, resulting in ASA syndrome presenting as cervical myelopathy (Figure 10) (113, 114). At this time, the subclavian artery should be reconstructed, and the steal path should be occluded (114).

When the ASA acts as a collateral channel, aneurysms can occur on the ASA due to hemodynamic stress (Figure 9C) (115). ASA aneurysms can be coiled in selected cases (Figure 11) $(116,117)$. However, due to the tortuous path and remote location, coiling is often difficult and impossible because EVT

\section{REFERENCES}

1. Ali F, Reddy V, Dublin AB. Anatomy, Back, Anterior Spinal Artery. Treasure Island, FL: StatPearls (2021).

2. Mizutani K, Consoli A, Maria FD, Condette Auliac S, Boulin A, Coskun O, et al. Intradural spinal cord arteriovenous shunts in a personal series of 210 patients: novel classification with emphasis on anatomical disposition and angioarchitectonic distribution, related to spinal cord histogenetic units. $J$ Neurosurg Spine. (2021) 34: 920-30. doi: 10.3171/2020.9.SPINE201258

3. Yamazaki D, Hanaoka Y, Koyama JI, Suzuki Y, Agata M, Abe D, et al. Intraspinal canal platform system for coil embolization of anterior spinal artery aneurysm associated with spinal cord arteriovenous malformation: a case report and literature review. Br J Neurosurg. (2021) 1-6. doi: 10.1080/02688697.2021.1910201

4. Abdalkader M, Samuelsen BT, Moore JM, Cervantes-Arslanian A, Ong CJ, Setty BN, et al. Ruptured spinal aneurysms: diagnosis and management paradigms. World Neurosurg. (2021) 146:e368-77. doi: 10.1016/j.wneu.2020.10.098

5. Kang HS, Han MH, Kim SH, Kwon OK, Roh HG, Koh YC. Anterior spinal artery as a collateral channel in cases of bilateral vertebral arterial steno-occlusive diseases. AJNR Am J Neuroradiol. (2007) 28:222-5.

6. Hiramatsu M, Sugiu $K$, Ishiguro $T$, Kiyosue $H$, Sato $K$, Takai $\mathrm{K}$, et al. Angioarchitecture of arteriovenous fistulas at the craniocervical junction: a multicenter cohort study of 54 patients. J Neurosurg. (2018) 128:1839-49. doi: 10.3171/2017.3.JNS1 63048

7. Dmytriw AA, Kapadia A, Enriquez-Marulanda A, Parra-Farinas C, Kuhn AL, Nicholson PJ, et al. Vertebral artery aneurysms and the risk of cord infarction following spinal artery coverage during flow diversion. J Neurosurg. (2020) 134:961-70. doi: 10.3171/2020.1.JNS193293

8. Yu JX, He C, Ye M, Li GL, Bian LS, Yang F, et al. The efficacy and deficiency of contemporary treatment for spinal cord arteriovenous shunts. Brain. (2021). doi: 10.1093/brain/awab237

9. Rojas S, Ortega M, Rodriguez-Baeza A. Anatomical study of the pial arterial network in human spinal cords. Clin Anat. (2021) 34:596604. doi: $10.1002 / \mathrm{ca} .23622$ has a low likelihood of parent artery preservation with the latter option (118).

\section{SUMMARY}

The cervical ASA is a very important artery. It can be involved in many cervical vascular diseases and has many different roles. In AVF and AVM, the cervical ASA often acts as an accomplice or victim because it acts as the feeder. In ASA aneurysm, the cervical ASA is a victim. During EVT for VA diseases, the cervical ASA ostia can be covered or occluded. In such cases, the ASA is a victim. In VA occlusion, the cervical ASA can serve as a collateral channel to provide blood flow to the posterior circulation. In this situation, the cervical ASA plays the role of a friend. In summary, EVT for cervical spinal vascular diseases should be determined "case by case," and damage to the ASA axis should be avoided.

\section{AUTHOR CONTRIBUTIONS}

JY contributed to the conception, design of the manuscript, and critically revised the manuscript. $\mathrm{KZ}$ and $\mathrm{CL}$ wrote the manuscript. $\mathrm{KH}$ and $\mathrm{CL}$ collected the medical records of the patients. All authors approved the final version of this manuscript.

10. Arslan M, Acar HI, Comert A, Tubbs RS. The cervical arteries: an anatomical study with application to avoid the nerve root and spinal cord blood supply. Turk Neurosurg. (2018) 28:234-40. doi: 10.5137/1019-5149.JTN.19469-16.1

11. Ravina K, Strickland BA, Rennert RC, Fredrickson V, Bakhsheshian J, Chien $\mathrm{M}$, et al. Fusiform vertebral artery aneurysms involving the posterior inferior cerebellar artery origin associated with the sole angiographic anterior spinal artery origin: technical case report and treatment paradigm proposal. $J$ Neurosurg. (2018) 131: 1324-30. doi: 10.3171/2018.5.JNS18681

12. Rodriguez-Baeza A, Muset-Lara A, Rodriguez-Pazos M, Domenech-Mateu JM. Anterior spinal arteries. Origin and distribution in man. Acta Anat. (1989) 136:217-21. doi: 10.1159/000146889

13. Santos-Franco JA, de Oliveira E, Mercado R, Ortiz-Velazquez RI, RevueltaGutierrez R, Gomez-Llata S. Microsurgical considerations of the anterior spinal and the anterior-ventral spinal arteries. Acta Neurochir. (2006) 148:329-38, discussion 38. doi: 10.1007/s00701-005-0663-7

14. Sheehy NP, Boyle GE, Meaney JF. Normal anterior spinal arteries within the cervical region: high-spatial-resolution contrastenhanced three-dimensional MR angiography. Radiology. (2005) 236:637-41. doi: 10.1148/radiol.2362040804

15. Kanazawa J, Yan J, Hitomi J. Differences in distribution of anterior segmental medullary arteries in the cervical and thoracolumbar spinal cord: the "inseln" were characteristics in the cervical spinal cord. Anat Sci Int. (2020) 95:97103. doi: 10.1007/s12565-019-00498-y

16. Dunbar L, Vidakovic H, Loffler S, Hammer N, Gille O, Boissiere L, et al. Anterior cervical spine blood supply: a cadaveric study. Surg Radiol Anat. (2019) 41:607-11. doi: 10.1007/s00276-019-02236-5

17. Oh SH, Perin NI, Cooper PR. Quantitative three-dimensional anatomy of the subaxial cervical spine: implication for anterior spinal surgery. Neurosurgery. (1996) 38:1139-44. doi: 10.1227/00006123-199606000-00016

18. Inci S, Bertan V, Cila A. Angiographically occult epidural arteriovenous fistula of the craniocervical junction. Surg Neurol. (2002) 57:167-73, discussion 73. doi: 10.1016/S0090-3019(02)00631-6

19. Lasjaunias $\mathrm{P}$, Vallee B, Person H, Ter Brugge K, Chiu M. The lateral spinal artery of the upper cervical spinal cord. Anatomy, normal variations, and angiographic aspects. J Neurosurg. (1985) 63:23541. doi: 10.3171/jns.1985.63.2.0235 
20. Gailloud P. The supreme intercostal artery includes the last cervical intersegmental artery (C7) - angiographic validation of the intersegmental nomenclature proposed by Dorcas Padget in 1954. Anat Rec. (2014) 297:8108. doi: 10.1002/ar.22893

21. Boeris D, Mortimer A, Sakthithasan M, Evins AI, Sandeman D, Renowden S. Conservative management of a post-traumatic pseudoaneurysm of the artery of cervical enlargement-anterior spinal artery junction. BMJ Case Rep. (2015) 1-3. doi: 10.1136/bcr-2015-011662

22. Sherman PM, Gailloud P. Artery of the cervical enlargement originating from the inferior thyroid artery: an angiographic observation. J Vasc Interv Radiol. (2004) 15:648-50. doi: 10.1016/S1051-0443(07)60341-8

23. Miller DL. Direct origin of the artery of the cervical enlargement from the left subclavian artery. AJNR Am J Neuroradiol. (1993) 14:242-4.

24. Matsubara N, Miyachi S, Okamaoto T, Izumi T, Asai T, Yamanouchi $\mathrm{T}$, et al. Spinal cord infarction is an unusual complication of intracranial neuroendovascular intervention. Interv Neuroradiol. (2013) 19:500-5. doi: 10.1177/159101991301900416

25. Brinjikji W, Colombo E, Lanzino G. Clinical and angioarchitectural characteristics of spinal vascular malformations of the cervical spine. J Neurosurg Spine. (2020) 32:755-62. doi: 10.3171/2019.11.SPINE 19798

26. Dabus G, Nimmagadda A, Russell EJ. Cervical epidural arteriovenous fistula presenting with radiculopathy: transvenous embolization using Onyx. Interv Neuroradiol. (2011) 17:380-5. doi: 10.1177/159101991101700317

27. Fujimoto S, Takai K, Nakatomi H, Kin T, Saito N. Three-dimensional angioarchitecture and microsurgical treatment of arteriovenous fistulas at the craniocervical junction. J Clin Neurosci. (2018) 53:140-6. doi: 10.1016/j.jocn.2018.04.065

28. Takai K. Spinal arteriovenous shunts: angioarchitecture and historical changes in classification. Neurol Med Chir. (2017) 57:356-65. doi: 10.2176/nmc.ra.2016-0316

29. Noh T, Chandra R, Kim J, Lee I. A case of symptomatic spinal dural arteriovenous fistula after high-volume lumbar puncture. Surg Neurol Int. (2017) 8:164. doi: 10.4103/sni.sni_474_16

30. Krings T, Geibprasert S. Spinal dural arteriovenous fistulas. AJNR Am J Neuroradiol. (2009) 30:639-48. doi: 10.3174/ajnr.A1485

31. Park SB, Han MH, Jahng TA, Kwon BJ, Chung CK. Spinal dural arteriovenous fistulas: clinical experience with endovascular treatment as a primary therapeutic modality. J Korean Neurosurg Soc. (2008) 44:3649. doi: 10.3340/jkns.2008.44.6.364

32. Koch MJ, Stapleton CJ, Agarwalla PK, Torok C, Shin JH, Coumans JV, et al. Patel Open and endovascular treatment of spinal dural arteriovenous fistulas: a 10-year experience. J Neurosurg Spine. (2017) 26:519-23. doi: 10.3171/2016.9.SPINE16394

33. Safaee MM, Clark AJ, Burkhardt JK, Winkler EA, Lawton MT. Timing, severity of deficits, and clinical improvement after surgery for spinal dural arteriovenous fistulas. J Neurosurg Spine. (2018) 29:85-91. doi: 10.3171/2017.11.SPINE17988

34. Su $\mathrm{H}, \mathrm{Xu} \mathrm{K}$, Wang $\mathrm{Y}, \mathrm{Yu}$ J. Is the middle meningeal artery the optimal path for dural arteriovenous fistula embolization? Front Neurol. (2021) 12:675355. doi: 10.3389/fneur.2021.675355

35. Jeon JP, Cho YD, Kim CH, Han MH. Complex spinal arteriovenous fistula of the craniocervical junction with pial and dural shunts combined with contralateral dural arteriovenous fistula. Interv Neuroradiol. (2015) 21:7337. doi: 10.1177/1591019915609128

36. Nguyen A, Maynard K III, Coggins W, Raghuram K. Successful embolization of an upper cervical spinal dural fistula despite anterior spinal artery anastomosis. Br J Neurosurg. (2019) 1-3. doi: 10.1080/02688697.2019.1694136

37. Adrianto Y, Yang KH, Koo HW, Park W, Jung SC, Park JE, et al. Concomitant origin of the anterior or posterior spinal artery with the feeder of a spinal dural arteriovenous fistula (SDAVF). J Neurointerv Surg. (2017) 9:40510. doi: 10.1136/neurintsurg-2016-012267

38. Hayward DM, Johans SJ, Rosenblum JD, Loftus CM, Ashley WW. Balloon-occlusion catheter onyx embolization of a spinal dural arteriovenous fistula presenting with subarachnoid hemorrhage in a pediatric patient. J Stroke Cerebrovasc Dis. (2016) 25:e46-9. doi: 10.1016/j.jstrokecerebrovasdis.2015.12.040
39. Onda K, Yoshida Y, Watanabe K, Arai H, Okada H, Terada T. High cervical arteriovenous fistulas fed by dural and spinal arteries and draining into a single medullary vein: report of 3 cases. J Neurosurg Spine. (2014) 20:25664. doi: 10.3171/2013.11.SPINE13402

40. Takai K, Komori $\mathrm{T}$, Kurita H, Kawai $\mathrm{K}$, Inoue $\mathrm{T}$, Taniguchi M. Intradural radicular arteriovenous fistula that mimics dural arteriovenous fistula: report of three cases. Neuroradiology. (2019) 61:1203-8. doi: 10.1007/s00234-019-02275-0

41. Mathur S, Symons SP, Huynh TJ, Muthusami P, Montanera W, Bharatha A. First-pass contrast-enhanced MRA for pretherapeutic diagnosis of spinal epidural arteriovenous fistulas with intradural venous reflux. AJNR Am J Neuroradiol. (2017) 38:195-9. doi: 10.3174/ajnr. A5008

42. Yu JX, Hong T, Ma YJ, Ling F, Zhang HQ. A new type of spinal epidural arteriovenous fistulas causes spinal epidural hemorrhage: an analysis of five cases and natural history consideration. World Neurosurg. (2017) 103:3719. doi: 10.1016/j.wneu.2017.04.036

43. Brinjikji W, Yin R, Nasr DM, Lanzino G. Spinal epidural arteriovenous fistulas. J Neurointerv Surg. (2016) 8:130510. doi: 10.1136/neurintsurg-2015-012181

44. Asai J, Hayashi T, Fujimoto T, Suzuki R. Exclusively epidural arteriovenous fistula in the cervical spine with spinal cord symptoms: case report. Neurosurgery. (2001) 48:1372-5, discussion 5-6. doi: 10.1227/00006123-200106000-00043

45. Song Y, Cho SH, Lee DW, Sheen JJ, Shin JH, Suh DC. Osseous versus nonosseous spinal epidural arteriovenous fistulas: experiences of 13 patients. AJNR Am J Neuroradiol. (2019) 40:129-34. doi: 10.3174/ajnr.A5904

46. Suh DC, Choi CG, Sung KB, Kim KK, Rhim SC. Spinal osseous epidural arteriovenous fistula with multiple small arterial feeders converging to a round fistular nidus as a target of venous approach. AJNR Am J Neuroradiol. (2004) 25:69-73.

47. Takai K, Shojima M, Imai H, Saito N, Taniguchi M. Microsurgical and endovascular treatments of spinal extradural arteriovenous fistulas with or without intradural venous drainage. World Neurosurg. (2018) 111:e81929. doi: 10.1016/j.wneu.2017.12.162

48. Rangel-Castilla L, Holman PJ, Krishna C, Trask TW, Klucznik RP, Diaz OM. Spinal extradural arteriovenous fistulas: a clinical and radiological description of different types and their novel treatment with Onyx. $J$ Neurosurg Spine. (2011) 15:541-9. doi: 10.3171/2011.6.SPINE10695

49. Takai K, Taniguchi M. Comparative analysis of spinal extradural arteriovenous fistulas with or without intradural venous drainage: a systematic literature review. Neurosurg Focus. (2012) 32:E8. doi: 10.3171/2012.2.FOCUS1216

50. Nakagawa I, Park HS, Hironaka Y, Wada T, Kichikawa K, Nakase H. Cervical spinal epidural arteriovenous fistula with coexisting spinal anterior spinal artery aneurysm presenting as subarachnoid hemorrhage-case report. J Stroke Cerebrovasc Dis. (2014) 23:e461-5. doi: 10.1016/j.jstrokecerebrovasdis.2014.07.012

51. Yoshida K, Sato S, Inoue $\mathrm{T}$, Ryu B, Shima S, Mochizuki $\mathrm{T}$, et al. Transvenous embolization for craniocervical junction epidural arteriovenous fistula with a pial feeder aneurysm. Interv Neuroradiol. (2020) 26:170-7. doi: 10.1177/1591019919874571

52. Huang W, Gross BA, Du R. Spinal extradural arteriovenous fistulas: clinical article. J Neurosurg Spine. (2013) 19:58290. doi: 10.3171/2013.8.SPINE13186

53. Goto Y, Hino A, Shigeomi Y, Oka H. Surgical management for craniocervical junction arteriovenous fistula targeting the intradural feeder. World Neurosurg. (2020) 144:e685-92. doi: 10.1016/j.wneu.2020. 09.041

54. Elkordy A, Endo T, Sato K, Sonoda Y, Takahashi A, Tominaga T. Exclusively epidural spinal metameric arteriovenous shunts: case report and literature review. Spine J. (2015) 15:e15-22. doi: 10.1016/j.spinee.2014.11.022

55. Shetty GS, Singh V, Prasad SN, Phadke RV, Neyaz Z, Udiya A, et al. Spinal epidural fistulas-a separate entity to dural fistulas with different angioarchitecture and treatment approach. World Neurosurg. (2021) 149:e600-e11. doi: 10.1016/j.wneu.2021.01.126

56. Umana GE, Scalia G, Chaurasia B, Fricia M, Passanisi M, Graziano F, et al. Perimedullary arteriovenous fistulas of the craniovertebral junction: 
a systematic review. J Craniovertebr Junction Spine. (2020) 11:15762. doi: $10.4103 /$ jcvjs.JCVJS_106_20

57. Ji T, Guo Y, Shi L, Yu J. Study and therapeutic progress on spinal cord perimedullary arteriovenous fistulas. Biomed Rep. (2017) 7:21420. doi: 10.3892/br.2017.951

58. Endo T, Shimizu H, Sato K, Niizuma K, Kondo R, Matsumoto $Y$, et al. Cervical perimedullary arteriovenous shunts: a study of 22 consecutive cases with a focus on angioarchitecture and surgical approaches. Neurosurgery. (2014) 75:238-49, discussion 49. doi: 10.1227/NEU.00000000000 00401

59. Spetzler RF, Detwiler PW, Riina HA, Porter RW. Modified classification of spinal cord vascular lesions. J Neurosurg. (2002) 96:145-56. doi: 10.3171/spi.2002.96.2.0145

60. Kim LJ, Spetzler RF. Classification and surgical management of spinal arteriovenous lesions: arteriovenous fistulae and arteriovenous malformations. Neurosurgery. (2006) 59:S195-201, discussion S3-13. doi: 10.1227/01.NEU.0000237335.82234.CE

61. Cho WS, Kim KJ, Kwon OK, Kim CH, Kim J, Han MH, et al. Clinical features and treatment outcomes of the spinal arteriovenous fistulas and malformation: clinical article. J Neurosurg Spine. (2013) 19:20716. doi: $10.3171 / 2013.4$. SPINE12732

62. Roccatagliata L, Kominami S, Krajina A, Sellar R, Soderman M, van den Berg $\mathrm{R}$, et al. Spinal cord arteriovenous shunts of the ventral (anterior) sulcus: anatomical, clinical, and therapeutic considerations. Neuroradiology. (2017) 59:289-96. doi: 10.1007/s00234-017-1789-z

63. Meng X, Zhang H, Wang Y, Ye M, He C, Du J, et al. Perimedullary arteriovenous fistulas in pediatric patients: clinical, angiographical, and therapeutic experiences in a series of 19 cases. Childs Nerv Syst. (2010) 26:889-96. doi: 10.1007/s00381-009-1071-8

64. Casasco A, Guimaraens L, Senturk C, Cotroneo E, Gigli R, Theron J. Endovascular treatment of cervical giant perimedullary arteriovenous fistulas. Neurosurgery. (2012) 70:141-9, discussion 9. doi: 10.1227/NEU.0b013e31822ec19e

65. Ioannidis I, Sfakianos G, Nasis N, Prodromou P, Andreou A. Successful embolization of a giant perimedullary arteriovenous fistula of the cervical spine in a 6-year-old child. Childs Nerv Syst. (2007) 23:132730. doi: 10.1007/s00381-007-0385-7

66. Zozulya YP, Slin'ko EI, Al-Qashqish II. Spinal arteriovenous malformations: new classification and surgical treatment. Neurosurg Focus. (2006) 20:E7. doi: 10.3171/foc.2006.20.5.8

67. Rangel-Castilla L, Russin JJ, Zaidi HA, Martinez-Del-Campo E, Park MS, Albuquerque FC, et al. Contemporary management of spinal AVFs and AVMs: lessons learned from 110 cases. Neurosurg Focus. (2014) 37:E14. doi: 10.3171/2014.7.FOCUS14236

68. Ohata K, Takami T, El-Naggar A, Morino M, Nishio A, Inoue $\mathrm{Y}$, et al. Posterior approach for cervical intramedullary arteriovenous malformation with diffuse-type nidus. Report of three cases. J Neurosurg. (1999) 91:10511. doi: $10.3171 /$ spi.1999.91.1.0105

69. Velat GJ, Chang SW, Abla AA, Albuquerque FC, McDougall CG, Spetzler RF. Microsurgical management of glomus spinal arteriovenous malformations: pial resection technique: clinical article. J Neurosurg Spine. (2012) 16:52331. doi: 10.3171/2012.3.SPINE11982

70. Ducruet AF, Crowley RW, McDougall CG, Albuquerque FC. Endovascular management of spinal arteriovenous malformations. J Neurointerv Surg. (2013) 5:605-11. doi: 10.1136/neurintsurg-2012-010487

71. Narayanan S, Hurst RW, Abruzzo TA, Albuquerque FC, Blackham KA, Bulsara KR, et al. Standard of practice: embolization of spinal arteriovenous fistulae, spinal arteriovenous malformations, and tumors of the spinal axis. J Neurointerv Surg. (2013) 5:3-5. doi: 10.1136/neurintsurg-2012-0 10551

72. Corkill RA, Mitsos AP, Molyneux AJ. Embolization of spinal intramedullary arteriovenous malformations using the liquid embolic agent, onyx: a singlecenter experience in a series of 17 patients. J Neurosurg Spine. (2007) 7:478-85. doi: 10.3171/SPI-07/11/478

73. Kitamura G, Jacobson JP, Zouros A, Neglio H. Improved neurological function in a paediatric patient following Onyx embolization of a cervical glomus arteriovenous malformation. J Neurointerv Surg. (2010) 2:3948. doi: $10.1136 /$ jnis. 2009.001453
74. Flores BC, Klinger DR, White JA, Batjer HH. Spinal vascular malformations: treatment strategies and outcome. Neurosurg Rev. (2017) 40:15-28. doi: 10.1007/s10143-016-0713-z

75. Rodesch G, Hurth M, Alvarez H, Lasjaunias P. Embolisation of spinal cord arteriovenous malformations with glue through the anterior spinal axis. Review of 20 Cases. Interv Neuroradiol. (1997) 3:13143. doi: $10.1177 / 159101999700300205$

76. Acewicz A, Richter P, Tykocki T, Czepiel W, Ryglewicz D, Dowzenko A. Endovascular treatment of cervical intramedullary arteriovenous malformation. Neurol Neurochir Pol. (2014) 48:223-7. doi: 10.1016/j.pjnns.2014.04.002

77. Kim J, Lee JB, Cho TH, Hur JW. Incidental occlusion of anterior spinal artery due to onyx reflux in embolization of spinal type II arteriovenous malformation. Eur Spine J. (2017) 26:75-9. doi: 10.1007/s00586-0164767-y

78. Ye ZP, Yang XY, Li WS, Hou B, Guo Y. Microsurgical resection of cervical spinal cord arteriovenous malformations: report of 6 cases. World Neurosurg. (2016) 96:362-9. doi: 10.1016/j.wneu.2016.09.022

79. Jung SC, Song Y, Cho SH, Kim J, Noh SY, Lee SH, et al. Endovascular management of aneurysms associated with spinal arteriovenous malformations. J Neurointerv Surg. (2018) 10:198-203. doi: 10.1136/neurintsurg-2017-013150

80. Madhugiri VS, Ambekar S, Roopesh Kumar VR, Sasidharan GM, Nanda A. Spinal aneurysms: clinicoradiological features and management paradigms. J Neurosurg Spine. (2013) 19:34-48. doi: 10.3171/2013.3.SPINE 121026

81. Karakama J, Nakagawa K, Maehara T, Ohno K. Subarachnoid hemorrhage caused by a ruptured anterior spinal artery aneurysm. Neurol Med Chir. (2010) 50:1015-9. doi: 10.2176/nmc.50.1015

82. Pahl FH, de Oliveira MF, Rotta MA, Dias GM, Rezende AL, Rotta JM. Spontaneous resolution of an isolated cervical anterior spinal artery aneurysm after subarachnoid hemorrhage. Surg Neurol Int. (2014) 5:139. doi: 10.4103/2152-7806.141776

83. Baldassarre B, Balestrino A, D’Andrea A, Anania P, Ceraudo M, Truffelli $\mathrm{M}$, et al. Management of spinal aneurysms associated with arteriovenous malformations: systematic literature review and illustrative case. Eur Spine J. (2021). doi: 10.1007/s00586-021-06881-6

84. Kurokawa Y, Ikawa F, Hamasaki O, Hidaka T, Yonezawa U, Komiyama M. A case of cervical spinal dural arteriovenous fistula with extradural drainage presenting with subarachnoid hemorrhage due to a ruptured anterior spinal artery aneurysm. No Shinkei Geka. (2015) 43:80311. doi: $10.11477 / \mathrm{mf} .1436203125$

85. Gross BA, Du R. Spinal pial (type IV) arteriovenous fistulae: a systematic pooled analysis of demographics, hemorrhage risk, and treatment results. Neurosurgery. (2013) 73:141-51, discussion 51. doi: 10.1227/01.neu.0000429848.91707.73

86. Biondi A, Merland JJ, Hodes JE, Pruvo JP, Reizine D. Aneurysms of spinal arteries associated with intramedullary arteriovenous malformations. I. Angiographic and clinical aspects. AJNR Am J Neuroradiol. (1992) 13:913-22.

87. Konan AV, Raymond J, Roy D. Transarterial embolization of aneurysms associated with spinal cord arteriovenous malformations. Report of four cases. J Neurosurg. (1999) 90:148-54. doi: 10.3171/spi.1999.90.1.0148

88. Lavoie P, Raymond J, Roy D, Guilbert F, Weill A. Selective treatment of an anterior spinal artery aneurysm with endosaccular coil therapy. Case report. J Neurosurg Spine. (2007) 6:460-4. doi: 10.3171/spi.2007.6.5.460

89. Cobb M, Griffin A, Karikari I, Gonzalez LF. Endovascular treatment of ruptured enlarging dissecting anterior spinal artery aneurysm. World Neurosurg. (2020) 139:e658-62. doi: 10.1016/j.wneu.2020.04.100

90. Dabus G, Tosello RT, Pereira BJA, Linfante I, Piske RL. Dissecting spinal aneurysms: conservative management as a therapeutic option. J Neurointerv Surg. (2018) 10:451-4. doi: 10.1136/neurintsurg-2017-013566

91. Boeris D, Mortimer A, Sakthithasan M, Evins AI, Sandeman D, Renowden S. Conservative management of a post-traumatic pseudoaneurysm of the artery of cervical enlargement-anterior spinal artery junction. J Neurointerv Surg. (2016) 8:e14. doi: 10.1136/neurintsurg-2015-011662.rep

92. Simon-Gabriel CP, Urbach H, Meckel S. Ruptured fusiform aneurysm of the anterior spinal artery: successful treatment with flow diverter stent 
placed in the feeding vertebral artery. Clin Neuroradiol. (2018) 28:6136. doi: $10.1007 / \mathrm{s} 00062-018-0684-2$

93. Wang Y, Zhao C, Hao X, Wang C, Wang Z. Endovascular interventional therapy and classification of vertebral artery dissecting aneurysms. Exp Ther Med. (2014) 8:1409-15. doi: 10.3892/etm.2014.1961

94. Wu Y, Li W, Xie X, Jing Z, Lu W, Huang L. Endovascular treatment with tirofiban during the acute stage of cervical spinal cord infarction due to vertebral artery dissection. J Spinal Cord Med. (2020) 43:1303. doi: $10.1080 / 10790268.2017 .1422880$

95. Pigman EC, Shepherd SM. Cervical anterior spinal artery syndrome associated with cardiopulmonary arrest. Am J Emerg Med. (1991) 9:4524. doi: 10.1016/0735-6757(91)90213-4

96. Takahashi S, Yamada T, Ishii K, Saito H, Tanji H, Kobayashi T, et al. MRI of anterior spinal artery syndrome of the cervical spinal cord. Neuroradiology. (1992) 35:25-9. doi: 10.1007/BF00588273

97. Shi L, Xu K, Sun X, Yu J. Therapeutic progress in treating vertebral dissecting aneurysms involving the posterior inferior cerebellar artery. Int J Med Sci. (2016) 13:540-55. doi: 10.7150/ijms.15233

98. Masson C, Pruvo JP, Meder JF, Cordonnier C, Touze E, De La Sayette $\mathrm{V}$, et al. Spinal cord infarction: clinical and magnetic resonance imaging findings and short term outcome. J Neurol Neurosurg Psychiatry. (2004) 75:1431-5. doi: 10.1136/jnnp.2003.031724

99. Pathak M, Kim RC, Pribram H. Spinal cord infarction following vertebral angiography: clinical and pathological findings. J Spinal Cord Med. (2000) 23:92-5. doi: 10.1080/10790268.2000.11753514

100. Aihara M, Naito I, Shimizu T, Matsumoto M, Asakura K, Miyamoto N, et al. Predictive factors of medullary infarction after endovascular internal trapping using coils for vertebral artery dissecting aneurysms. J Neurosurg. (2018) 129:107-13. doi: 10.3171/2017.2.JNS162916

101. Tsuruta W, Yamamoto T, Ikeda G, Sato M, Ito Y, Takigawa T, et al. Spinal cord infarction in the region of the posterior spinal artery after embolization for vertebral artery dissection. Oper Neurosurg. (2018) 15:70110. doi: $10.1093 /$ ons/opy026

102. Shakir HJ, Rooney PJ, Rangel-Castilla L, Yashar P, Levy EI. Treatment of iatrogenic V2 segment vertebral artery pseudoaneurysm using Pipeline flowdiverting stent. Surg Neurol Int. (2016) 7:104. doi: 10.4103/2152-7806.196235

103. Wang CM, Tsai WL, Lo YL, Chen JY, Wong AM. Unilateral right occipital condyle to C2 level spinal cord infarction associated with ipsilateral vertebral artery stenosis and contralateral vertebral artery dissection: a case report. J Spinal Cord Med. (2011) 34:118-21. doi: 10.1179/107902610X12883422813543

104. Wang Z, Wang C, Li C, Shi M, Wang S, Yang Y. Stenting for symptomatic intracranial vertebrobasilar artery stenosis in northeast of china: a single-center study. Front Neurol. (2020) 11:609286. doi: 10.3389/fneur.2020.609286

105. Turnbull IM, Brieg A, Hassler O. Blood supply of cervical spinal cord in man. A microangiographic cadaver study. J Neurosurg. (1966) 24:95165. doi: 10.3171/jns.1966.24.6.0951

106. Fukui T, Takaki J, Okamoto K. Collateral formation from left lateral thoracic artery to the adamkiewicz artery. Aorta. (2020) 8:175-7. doi: $10.1055 / \mathrm{s}-0040-1721748$

107. Chiras J, Gaston A, Bouhours PG, Heraut LA, Henry P, Bories J, et al. An application of balloon probes. Preoperative electrophysiological test of the tolerance to temporal occlusion of the artery of cervical enlargement. Neurochirurgie. (1983) 29:289-93.

108. Sriganesh K, Chatterjee N, Singha S. Bispectral index monitoring facilitates early detection of catheter-induced vasospasm during neuro-endovascular procedures. Acta Anaesthesiol Scand.

(2009) 53:406-7. doi: 10.1111/j.1399-6576.2008.01827.x

109. Yamakawa H, Yoshimura S, Iwama T. Anterior spinal artery as a collateral channel in patients with acute bilateral vertebral artery occlusions. Two case reports. Neurol Med Chir. (2009) 49:354-8. doi: 10.2176/nmc.49.354

110. Xu K, Yu TC, Wang X, Yu JL. Bilateral carotid and vertebral rete mirabile associated with intracranial multiple hemorrhages: a case report and literature review. Int J Clin Exp Med. (2016) 9:12153-62.

111. Fukuda H, Hayashi K, Handa A, Kurosaki Y, Lo B, Yamagata S. Reflux of anterior spinal artery predicts recurrent posterior circulation stroke in bilateral vertebral artery disease. Stroke. (2015) 46:32635. doi: 10.1161/STROKEAHA.115.011246

112. Dubow J, Riina H, Patsalides A. Vertebral artery stenting in a patient with reversed flow in the anterior spinal artery. J Neurointerv Surg. (2012) 4:114-5. doi: 10.1136/jnis.2010.004150

113. Mohassel P, Wesselingh R, Katz Z, McArthur J, Gailloud P. Anterior spinal artery syndrome presenting as cervical myelopathy in a patient with subclavian steal syndrome. Neurol Clin Pract. (2013) 3:35860. doi: 10.1212/CPJ.0b013e318296f217

114. Rughani AI, Visioni A, Hamill RW, Tranmer BI. Subclavian artery stenosis causing transient bilateral brachial diplegia: an unusual cause of anterior spinal artery syndrome. J Neurosurg Spine. (2008) 9:1915. doi: 10.3171/SPI/2008/9/8/191

115. Ashour R, Filippidis A, Patel N. Ruptured anterior spinal artery aneurysm associated with bilateral vertebral artery occlusion treated by surgical clipping. World Neurosurg. (2015) 84:1178.e11-3. doi: 10.1016/j.wneu.2015.06.010

116. Glauser G, Hurst RW, Pukenas BA, Sedora-Roman NI, Kung D, Choudhri O. Subarachnoid hemorrhage as result of retrocorporeal artery aneurysm rupture: rare sequel of subclavian steal syndrome. World Neurosurg. (2020) 133:66-8. doi: 10.1016/j.wneu.2019.09.129

117. Shima S, Sato S, Motizuki T, Niimi Y. Endovascular treatment for ruptured cervical anterior spinal artery aneurysm caused by occlusive disease of bilateral vertebral arteries: a case report and literature review. Clin Neurol Neurosurg. (2021) 208:106862. doi: 10.1016/j.clineuro.2021.106862

118. Nagahata M, Kondo R, Mouri W, Sato A, Ito M, Sato S, et al. Bilateral carotid and vertebral rete mirabile presenting with subarachnoid hemorrhage caused by the rupture of spinal artery aneurysm. Tohoku J Exp Med. (2013) 230:2059. doi: $10.1620 /$ tjem. 230.205

Conflict of Interest: The authors declare that the research was conducted in the absence of any commercial or financial relationships that could be construed as a potential conflict of interest.

Publisher's Note: All claims expressed in this article are solely those of the authors and do not necessarily represent those of their affiliated organizations, or those of the publisher, the editors and the reviewers. Any product that may be evaluated in this article, or claim that may be made by its manufacturer, is not guaranteed or endorsed by the publisher.

Copyright $\odot 2021$ Zhang, Li, Hou and Yu. This is an open-access article distributed under the terms of the Creative Commons Attribution License (CC BY). The use, distribution or reproduction in other forums is permitted, provided the original author(s) and the copyright owner(s) are credited and that the original publication in this journal is cited, in accordance with accepted academic practice. No use, distribution or reproduction is permitted which does not comply with these terms. 